\title{
(ब)
}

AUTARQUIA ASSOCIADA À UNIVERSIDADE DE SÃO PAULO

\section{DESENVOLVIMENTO DO SISTEMA DE POTÊNCIA ELÉTRICA EM UMA UNIDADE MÓVEL DE IRRADIAÇÃO POR FEIXE DE ELÉTRONS PARA TRATAMENTO DE ÁGUAS RESIDUÁRIAS E EFLUENTES INDUSTRIAIS}

\author{
RENATO RACHE GASPAR
}

Dissertação apresentada como parte dos requisitos para obtenção do Grau de Mestre em Ciências na Área de Tecnologia Nuclear - Aplicações

Orientador:

Prof. Dr. Wilson Aparecido Parejo Calvo 
INSTITUTO DE PESQUISAS ENERGÉTICAS E NUCLEARES

Autarquia associada à Universidade de São Paulo

DESENVOLVIMENTO DO SISTEMA DE POTÊNCIA ELÉTRICA EM UMA UNIDADE MÓVEL DE IRRADIAÇÃO POR FEIXE DE ELÉTRONS PARA TRATAMENTO DE ÁGUAS RESIDUÁRIAS E EFLUENTES INDUSTRIAIS

\section{RENATO RACHE GASPAR}

Dissertação apresentada como parte dos requisitos para obtenção do Grau de Mestre em Ciências na Área de Tecnologia Nuclear - Aplicações

Orientador:

Prof. Dr. Wilson Aparecido Parejo Calvo 
Autorizo a reprodução e divulgação total ou parcial deste trabalho, para fins de estudo e pesquisa, desde que citada a fonte

Como citar:

GASPAR, R. R. Desenvolvimento do sistema de potência elétrica em uma unidade $m$ vel de irradiação por feixe de elétrons para tratamento de águas residuárias e e luentes industriais. 2018. 63 p. Dissertação (Mestrado em Tecnologia Nuclear), Instituto de Pesquisas Energéticas e Nucleares, IPEN-CNEN/SP, São Paulo.

Disponível em: <www.teses.usp.br> (data de consulta no formato: dd/mm/aaaa)

Ficha catalográfica elaborada pelo Sistema de geração automática da Biblioteca IPEN/USP, com os dados fornecidos pelo(a) autor(a)

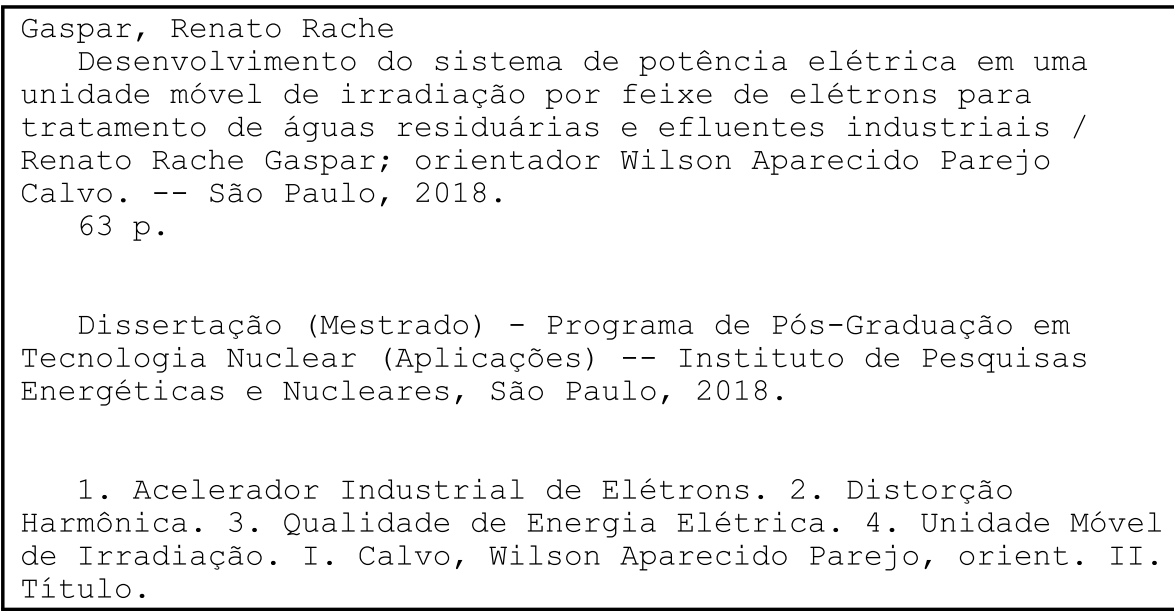




\section{AGRADECIMENTOS}

Ao meu orientador, Dr. Wilson Aparecido Parejo Calvo pela oportunidade, orientação e dedicação dada durante toda a Dissertação de Mestrado.

Ao M.Sc. Samir Luiz Somessari pelos ensinamentos e suporte técnico oferecidos no Centro de Tecnologia das Radiações do IPEN.

Ao Sr. Fernando J. F. Moreira pelo empenho na consolidação de parcerias entre instituições diversas que permitiu a realização deste Mestrado.

Ao Instituto de Pesquisas Energéticas e Nucleares (IPEN) pela oportunidade de realização da Dissertação de Mestrado.

À Faculdade de Medicina do Vale do Aço (UNIVAÇO) pela oportunidade em participação do convênio com o IPEN. 


\section{RESUMO}

GASPAR, R. R. Desenvolvimento do sistema de potência elétrica em uma unidade móvel de irradiação por feixe de elétrons para tratamento de águas residuárias e efluentes industriais. 2018. 62 p. Dissertação (Mestrado em Tecnologia Nuclear) - Instituto de Pesquisas Energéticas e Nucleares - IPENCNEN/SP. São Paulo.

O tratamento de águas residuárias e efluentes industriais por irradiação com feixe de elétrons é uma técnica promissora, porém pouco difundida em território Brasileiro. $\mathrm{O}$ projeto e a construção de uma unidade móvel contendo um acelerador industrial de elétrons de $700 \mathrm{keV}$ e $20 \mathrm{~kW}$, pelo Instituto de Pesquisas Energéticas e Nucleares (IPEN), é inovador para demonstrar os efeitos e resultados positivos dessa tecnologia. O propósito é deslocar a unidade móvel às diversas empresas com interesse em tratamento dos resíduos líquidos, conectar-se ao sistema elétrico da mesma e iniciar o processo de tratamento por ionização, por meio da irradiação com feixe de elétrons. A conexão da unidade móvel ao sistema elétrico local pode representar um desafio, pela grande diversidade de tensões e distâncias envolvidas, e também pelas grandes injeções de conteúdo harmônico gerado pelo acelerador de elétron que podem afetar as cargas do sistema industrial, comumente sensíveis. Neste trabalho realizou-se uma análise do sistema de potência da unidade móvel, quanto à capacidade de interrupção, seletividade da proteção e níveis de curto-circuito adequados de forma a assegurar uma maior confiabilidade na operação. Ao final, projetou-se e construiu-se o painel elétrico de controle da unidade móvel de irradiação. Além disso, na obtenção de parâmetros operacionais à unidade móvel, realizaram-se simulações e medições no acelerador industrial de elétrons de $1,5 \mathrm{MeV}$ e $37,5 \mathrm{~kW}$, instalado no Laboratório de Fontes Intensas de Radiação, do Centro de Tecnologia das Radiações, as quais demonstraram a necessidade da inserção de um filtro para redução dos índices de distorção nos harmônicos dessa instalação radiativa fixa no IPEN.

Palavras chaves: Acelerador industrial de elétrons, distorção harmônica, qualidade de energia elétrica, unidade móvel de irradiação. 


\begin{abstract}
GASPAR, R. R. Developing an electrical power system of a mobile electron beam accelerator to treatment of industrial wastewaters and effluents. 2018. 62 p. Dissertação (Mestrado em Tecnologia Nuclear) - Instituto de Pesquisas Energéticas e Nucleares - IPEN-CNEN/SP. São Paulo.
\end{abstract}

The treatment of wastewater and industrial effluents by electron beam irradiation is a promising technique, however, not very widespread in Brazilian territory. The design and a construction of a mobile unit containing an electron beam accelerator of $700 \mathrm{KeV}$ and $20 \mathrm{~kW}$, by the Nuclear and Energy Research Institute (IPEN) is innovative to demonstrate the effects and positive results of this technology. The aim is to move the mobile unit to several companies with interest in liquid waste treatment, and connect to the industry electrical system and start the ionization treatment process through electron beam. The mobile unit's connection to the local electrical system can be a challenge in behalf of the great diversity of voltages and distances involved, as well as the large injections of harmonic content generated by the electron beam accelerator that can affect sensitive loads in the industrial system. In this work, an analysis was made of the power system of the mobile unit, regarding interruption capacity, selectivity protection and adequate short circuit levels in order to assure a greater reliability in the operation. At the end, the control panel of the mobile unit, simulations and measurements were carried out at the $1.5 \mathrm{MeV}$ and $37.5 \mathrm{~kW}$ electron beam accelerator, installed at the Intensive Radiation Technology Center, which demonstrated the necessity of applying of a filter to reduce the measured harmonic distortion.

Keywords: Industrial electron accelerator, harmonic distortion, electric power quality, mobile irradiation unit. 


\section{LISTA DE FIGURAS}

Figura 1 - Acelerador de Elétrons Crockcroft-Walton [London Science Museum, 1937]

Figura 2 - Circuito dobrador de tensão simples utilizando diodos [desenvolvido pelo autor].

Figura 3 - Circuito multiplicador de tensão de três estágios [desenvolvido pelo autor].

Figura 4 - Tensão de entrada e saída do multiplicador de tensão com três estágios [simulado do software Alternative Transient Program (ATP)] 16

Figura 5 - Circuito de potência do Acelerador Industrial de Elétrons RDI DC 1500/25/4 (1,5 MeV, $25 \mathrm{~mA}$ e 37,5 kW) [7].

Figura 6 - Esquemático de um acelerador industrial de elétrons de $500 \mathrm{keV}\left[{ }^{8}\right] \ldots . .17$

Figura 7 - Dimensional da carreta projetada pela High Voltage Environmental Applications Inc. para a unidade móvel de irradiação por feixe de elétrons da Universidade de Miami [ $\left.{ }^{9}\right]$.

Figura 8 - Unidade móvel de irradiação por feixe de elétrons fabricada pela empresa E-ventus atual E-pura $\left[{ }^{10}\right]$. .20

Figura 9 - Diagrama unifilar da unidade móvel proposta (software PTW). .38

Figura 10 - Níveis de curtos-circuitos nos barramentos e contribuição de cada trecho para o curto (software PTW).

Figura 11 - Coordenograma do trecho acelerador de elétrons até a conexão com a rede externa.

Figura 12 - Coordenograma do trecho bomba de circulação de efluentes líquidos até a conexão com a rede externa.

Figura 13 - Transformador Isolador adquirido de 112,5 kVA para a unidade móvel.

Figura 14 - Pontos de ligação do enrolamento primário e barras de conexão.........43

Figura 15 - Quadro de distribuição adquirido para a unidade móvel. ......................44

Figura 16 - Detalhe do quadro de distribuição aberto .........................................4

Figura 17 - Medidor de energia Power Quality Meter (PQM) da marca GE@ . .........48

Figura 18 - Tela do software e medições no Centro de Tecnologia das Radiação.. 48

Figura 19 - Variação da distorção harmônica da corrente pela corrente do feixe de elétrons. 
Figura 20 - Variação da distorção harmônica da tensão pela corrente do feixe de elétrons. 49

Figura 21 - Forma de onda típica da corrente na entrada do acelerador de elétrons.

Figura 22 - Forma de onda típica da tensão na entrada do acelerador de elétrons.50 Figura 23 - Espectro harmônico da corrente la mantendo o acelerador na condição $0,7 \mathrm{MeV}$ e $20 \mathrm{~mA}$ de energia e corrente de feixe respectivamente. .52

Figura 24 - Espectro harmônico da tensão Va mantendo o acelerador na condição $0,7 \mathrm{MeV}$ e $20 \mathrm{~mA}$ de energia e corrente de feixe respectivamente. .52

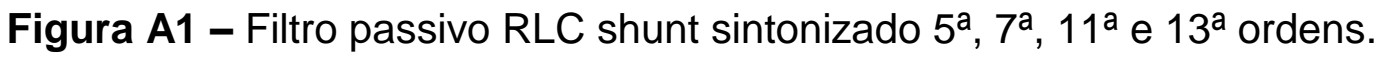
59

Figura A2 - Resposta em frequência do filtro, simulado com o software ATPdraw. Em vermelho, verde e azul os filtros de $5^{\circ}, 11^{\circ}$ e $23^{\circ}$ ordem respectivamente. 62 


\section{LISTA DE TABELAS}

Tabela 1 - Tensões Nominais Padronizadas no sistema elétrico nacional $\left[{ }^{16}\right]$........26

Tabela 2 - Cargas estimadas pertencentes a unidade móvel em desenvolvimento. 27

Tabela 3 - Características sugeridas dos cabos de entrada da unidade móvel. ......33

Tabela 4 - Características sugeridas para os disjuntores do quadro de distribuição.

Tabela 5 - Ajustes sugeridos na parametrização do disjuntor de entrada.

Tabela 6 - Limites harmônicos de tensão individual e da distorção total, publicados no guia IEEE Std. 519-2014 [23].

Tabela 7 - Limites harmônicos de corrente individual e da distorção total, publicados no guia IEEE Std. 519-2014 [23].

Tabela 8 - Limites harmônicos de corrente segundo IEC 61000-3-4 [ $\left.{ }^{24}\right]$. 46

Tabela 9 - Comparação entre valores medidos no acelerador industrial de elétrons e os valores normatizados de distorção harmônica de corrente. .50

Tabela 10 - Comparação entre valores medidos no acelerador industrial de elétrons e os valores normatizados de distorção harmônica de tensão .51

Tabela A1 - Características sugeridas para o filtro harmônico projetado. 62 


\section{SUMÁRIO}

Página

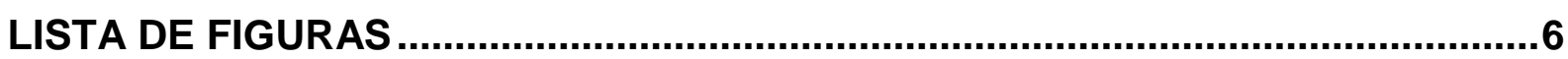

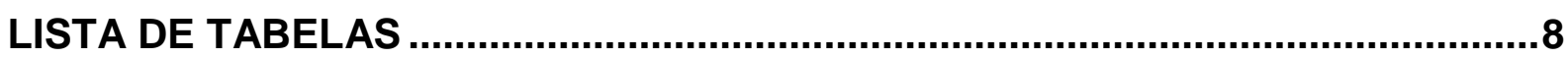

1. INTRODUÇÃO

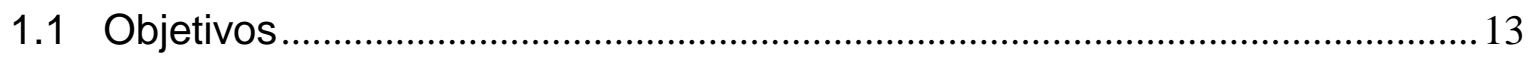

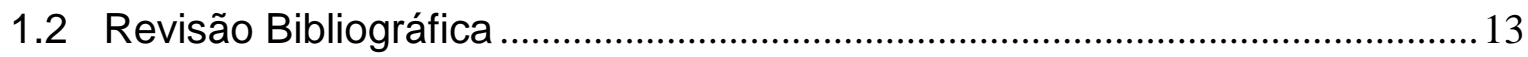

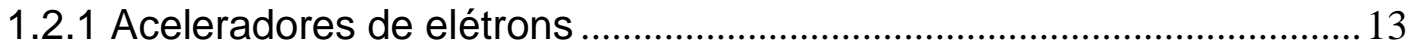

1.2.2 Sistema de controle e proteção ............................................................... 18

1.2.3 Unidades móveis de irradiação ................................................................... 19

2. UNIDADE MÓVEL EM DESENVOLVIMENTO PELO IPEN .............................20

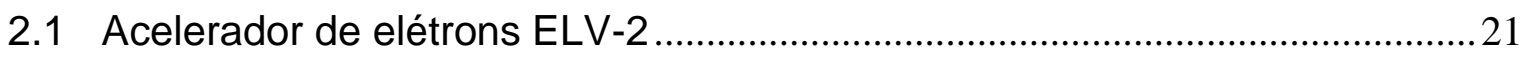

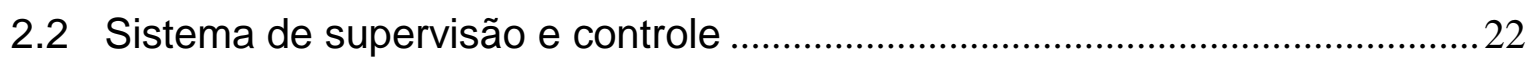

2.3 Sistema de circulação do efluente líquido e demais equipamentos ................23

3. ANÁLISE DA CONEXÃO ELÉTRICA DA UNIDADE MÓVEL ….....................23

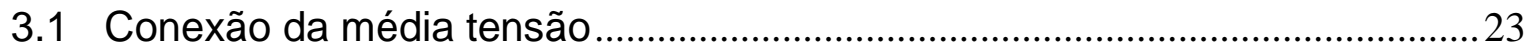

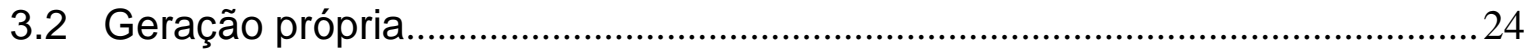

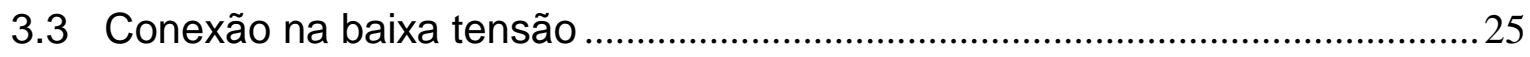

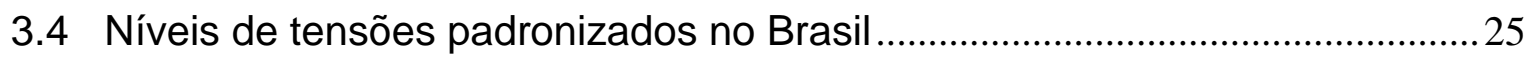

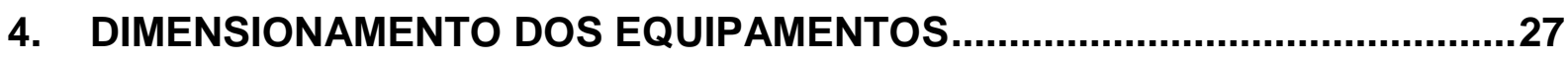

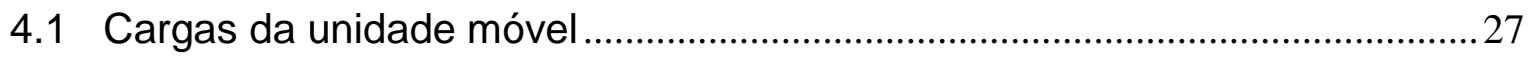

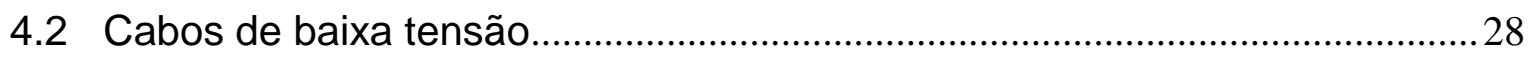

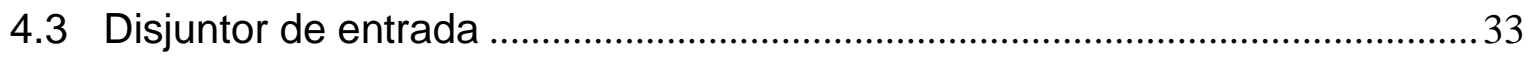

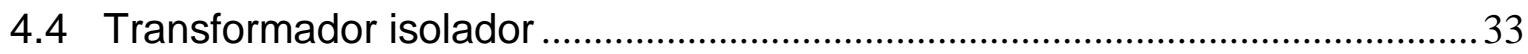

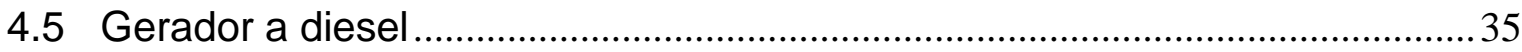

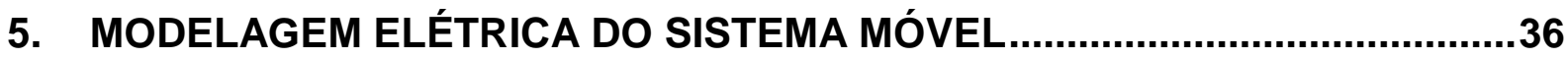

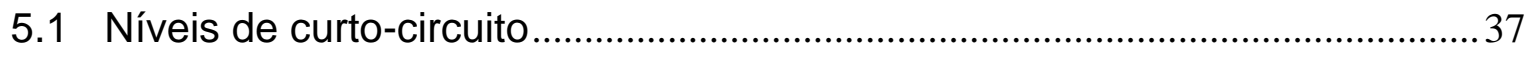

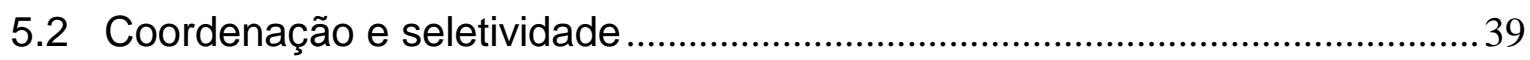

6. DESENVOLVIMENTO E AQUISIÇÃO DOS EQUIPAMENTOS .......................42 
7. HARMÔNICOS

8. MEDIÇÕES REALIZADAS NO ACELERADOR DE ELÉTRONS

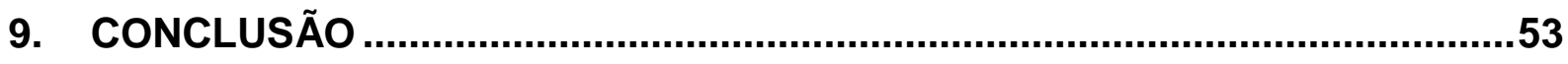

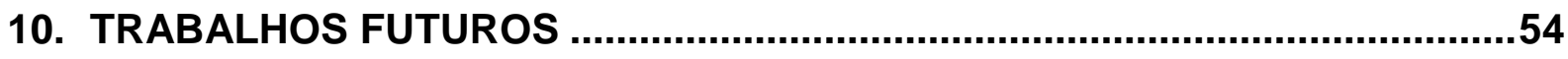

ANEXO A - DIMENSIONAMENTO DE FILTROS HARMÔNICOS ...........................59 


\section{INTRODUÇÃO}

Atualmente, grande parte das indústrias necessita tratar os resíduos sólidos, líquidos e/ou gasosos contaminados durante as etapas do processo de fabricação. $\mathrm{O}$ tratamento incorreto desses resíduos pode ocasionar danos tanto à vida aquática quanto à humana, além de permitir a aplicação de multas altas pelos órgãos ambientais responsáveis.

Os tratamentos dos resíduos industriais são classificados de acordo com as técnicas utilizadas. Podem ser por meio de reações químicas (químico), processos naturais (biológico) ou por processos de separação (físico). Desse último, englobamse as técnicas de remediação ou eliminação, por meio da radiação ionizante por feixe de elétrons.

A irradiação com feixe de elétrons pode ocasionar diversos efeitos dependendo da energia relacionada ao elétron. No caso específico do tratamento de efluentes industriais, o objetivo é a degradação de compostos orgânicos, muitas vezes com alto grau de toxicidade, de maneira a se obter o menor impacto ambiental possível, ou seja, minimizando-se os gases gerados ao longo do processo e permitindo o reuso das águas do efluente tratado. Por se tratar de uma técnica rápida e não seletiva, sua velocidade de processamento é superior em comparação à dos métodos tradicionais, o que permite alcançar custos-benefícios vantajosos quando utilizado para grandes volumes de efluentes $\left[{ }^{1,2}\right]$.

O processo de oxidação química de compostos orgânicos tóxicos em moléculas mais simples é muito promissor para recuperação do meio ambiente. $\mathrm{O}$ caminho mais eficiente para a oxidação é por ataque com radicais hidroxilas $(\mathrm{OH}$.), sendo que existem vários processos para gerar esses radicais em água, que são conhecidos como Processos de Oxidação Avançada (POA) e utilizam o ozônio, o peróxido de hidrogênio, a radiação ultravioleta (UV) e a radiação ionizante. A irradiação da água por feixe de elétrons é um método muito eficiente de geração desses radicais e, portanto, de oxidação e destruição das moléculas de compostos orgânicos [3].

O programa de pesquisa do IPEN-CNEN/SP teve início em 1992, utilizando o acelerador industrial de elétrons da Radiation Dynamics de $1,5 \mathrm{MeV}$ de energia e $37 \mathrm{~kW}$ 
de potência de feixe, e nos primeiros trabalhos realizados utilizou-se da esteira do acelerador, irradiando amostras em bateladas. Os trabalhos iniciais incluem aplicação da radiação ionizante para desinfecção de esgotos domésticos e lodos e para a degradação de tricloroetileno (TCE) e percloroetileno (PCE) em água potável. Em setembro de 1993 concluiu-se a construção de uma planta piloto para tratamento de efluentes líquidos, projetada para tratar cerca de $3 \mathrm{~m}^{3} / \mathrm{h}$ de efluentes. A planta piloto é constituída de tanques de armazenagem para produtos não processados e beneficiados e do sistema de bombeamento para homogeneização e para transporte do efluente até o sistema de irradiação instalado no bunker do acelerador industrial de elétrons. O sistema de irradiação foi construído em uma geometria tal que permite a interação do feixe de elétrons no contra fluxo do efluente a ser irradiado. Essa configuração aumenta o tempo de exposição do efluente no campo de bombardeamento com feixe de elétrons e consequentemente a eficiência do mesmo[ $\left.{ }^{4}\right]$.

O equipamento responsável pela emissão dos elétrons é o acelerador industrial de elétrons, também conhecido pela sigla em Inglês EBA (Electron Beam Accelerator). O processo de tratamento de resíduos líquidos, sólidos e gasosos por meio da utilização dos aceleradores de elétrons não é utilizado na prática no Brasil, em função de diversos fatores, dentre eles: a falta de difusão da tecnologia, de produtores nacionais do equipamento e falta de mão de obra especializada em O\&M (Operação e Manutenção); o alto capital inicial de investimento e a falta de infraestrutura nas indústrias para suportar um equipamento nas dimensões requeridas, além da necessidade de se atender aos requisitos de licenciamento e controle de operação da instalação radiativa junto à Comissão Nacional de Energia Nuclear (CNEN).

Nesse cenário, o Instituto de Pesquisas Energéticas Nucleares (IPEN) consolidou parcerias com empresas nacionais (SABESP, Truckvan e Petrobrás) e internacionais (EBTech Co., Itd.), além do SENAI, visando desenvolver e construir uma unidade móvel de irradiação com feixe de elétrons, que prestaria atendimento pontual no tratamento de efluentes industriais e divulgaria essa tecnologia em diversas áreas do Brasil com demonstrativos práticos das vantagens de sua utilização. A Agência Internacional de Energia Atômica (AIEA) financia no IPEN o "Projeto Nacional de Inovação BRA/1/035 - Unidade móvel de irradiação com acelerador de elétrons para tratamento de efluentes industriais para fins de reutilização", no período de 2016 a 2018. 
A unidade móvel consiste em um centro de irradiação móvel, cujo compartimento de carga da carreta acomoda todos os equipamentos necessários ao tratamento de resíduos sólidos, líquidos ou gasosos por feixe de elétrons. O projeto idealizado prevê a divisão do compartimento nos seguintes módulos: a) sala de controle e divulgação técnico-científica; b) acelerador industrial de elétrons, unidades hidráulicas, sistema de ventilação, refrigeração e bunker com o sistema de irradiação; e c) transformador e quadro de distribuição elétrica, dentre outros equipamentos [ $\left.{ }^{4}\right]$.

\subsection{Objetivos}

O objetivo do trabalho é realizar uma análise do sistema de potência elétrica da Unidade Móvel de Irradiação com acelerador industrial de elétrons e desenvolver o projeto dos equipamentos necessários para conexão elétrica, de modo a permitir maior flexibilidade de utilização e propiciar maior confiabilidade na operação da instalação em virtude da carga elétrica exigida e dos altos índices de harmônicos gerados. Os equipamentos serão avaliados quanto à tensão de operação, capacidade de interrupção, seletividade da proteção e níveis de curto-circuito por meio de simulações e estudos com softwares específicos para garantir o correto dimensionamento.

Adicionalmente serão realizadas medições da qualidade de energia no acelerador industrial de elétrons do IPEN de fabricação da Radiation Dynamics Inc, energia até $1,5 \mathrm{MeV}$ e corrente do feixe de elétrons até $25 \mathrm{~mA}$, no intuito de investigar a natureza das correntes harmônicas geradas e avaliar a necessidade de equipamentos para controle do fator de potência e harmônicos.

\subsection{Revisão Bibliográfica}

\subsubsection{Aceleradores de elétrons}

Os aceleradores surgiram no final do século $\mathrm{XIX}$, na Universidade de Cambridge, Inglaterra, no Laboratório de Cavendish, com a intenção de acelerar partículas utilizando uma diferença de potencial, permitindo assim estudar o efeito 
gerado da colisão dessas partículas com materiais diversos. O primeiro acelerador criado, denominado Cockcroft and Walton's Voltage Multiplier, acelerava prótons com uma diferença de potencial inicial $200 \mathrm{kV}$, utilizando estágios de idênticos de capacitores e retificadores $\left.{ }^{5,6}\right]$. Na Figura 1 é mostrado o Acelerador Cockcroft \& Walton's construído em 1937, pertencente ao Museu Nacional de Ciência de Londres, na Inglaterra.

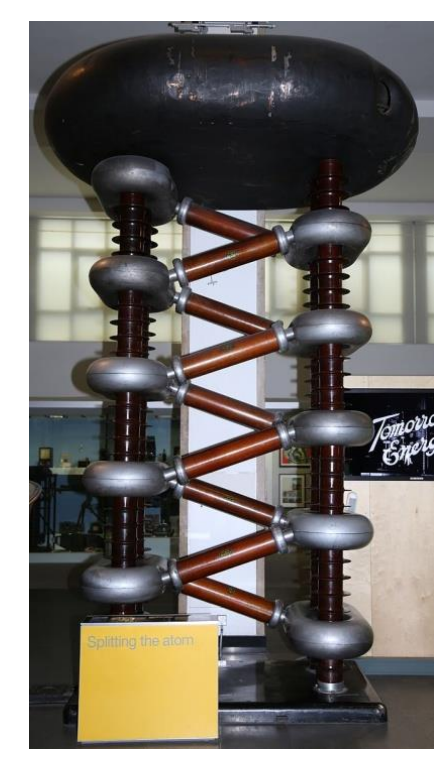

Figura 1 - Acelerador de Elétrons Crockcroft-Walton [London Science Museum, 1937]

O acelerador foi aprimorado posteriormente por Van de Graaff, que propôs a utilização de uma esteira rotativa de seda que circulava entre dois eletrodos, seguido por Rolf Wideröe, que criou o conceito de Betatron ou acelerador de indução. Hoje em dia, basicamente, os aceleradores são divididos em dois tipos: os que aceleram em linha reta (Lineares) e os que aceleram em linhas circulares (Acelerador Cíclotron). Também se classificam quanto ao tipo de partícula acelerada (alfa, beta ou prótons) e à energia final da partícula acelerada.

A utilização comercial de aceleradores industriais de elétrons iniciou-se somente no final dos anos 50, na aplicação de reticulação do polietileno, polímero básico utilizado na isolação e cobertura de fios e cabos isolados. Hoje em dia, o acelerador de elétrons é utilizado para os mais diversos fins, tais como radioesterilização de produtos médicos e tecidos biológicos, irradiação em alimentos, vidros, pedras preciosas, dentre outras aplicações.

O acelerador industrial de elétrons proposto para a unidade móvel pode ser dividido nos seguintes componentes: gerador de alta tensão, tubo acelerador e 
sistema de varredura. O sistema de alta tensão consiste em um circuito composto por retificadores e dobradores de tensão, que quando colocados em série formam os chamados circuitos multiplicadores de tensão. A alimentação desse circuito é feita por meio de um transformador de altas frequências. O tubo acelerador a vácuo consiste em um filamento de tungstênio que, quando aquecido, produz elétrons acelerados pela diferença de potencial gerada entre o ânodo e cátodo. O circuito gerador de alta tensão já mencionado é composto por uma série de retificadores dobradores de tensão. O circuito básico do dobrador é mostrado na Figura 2.

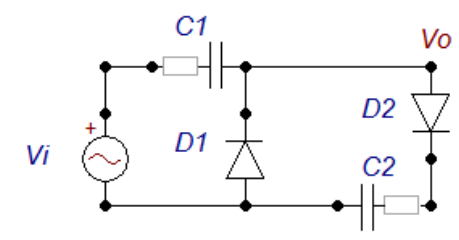

Figura 2 - Circuito dobrador de tensão simples utilizando diodos [desenvolvido pelo autor].

O funcionamento do circuito consiste em carregar com uma fonte alternada o capacitor C1 com a tensão máxima de pico durante o semiciclo positivo e carregar o capacitor C2 com a tensão mínima de pico durante o semiciclo negativo, obtendo assim uma tensão contínua em $V_{o}$ de magnitude duas vezes superior à tensão de pico da fonte.

Utilizando esta mesma lógica, faz-se então a associação de vários circuitos dobradores de tensão em série, onde a tensão de saída é proporcional ao número de estágios do circuito. Nas Figuras 3 e 4 são mostrados o circuito com três estágios e a forma de onda da tensão de entrada e saída. O circuito foi simulado empregando-se a fermenta computacional Alternative Transient Program (ATP).

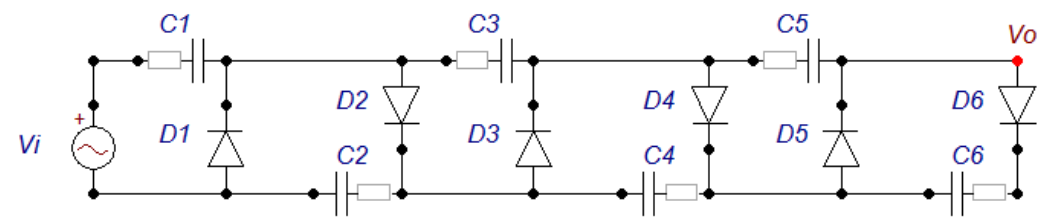

Figura 3 - Circuito multiplicador de tensão de três estágios [desenvolvido pelo autor]. 


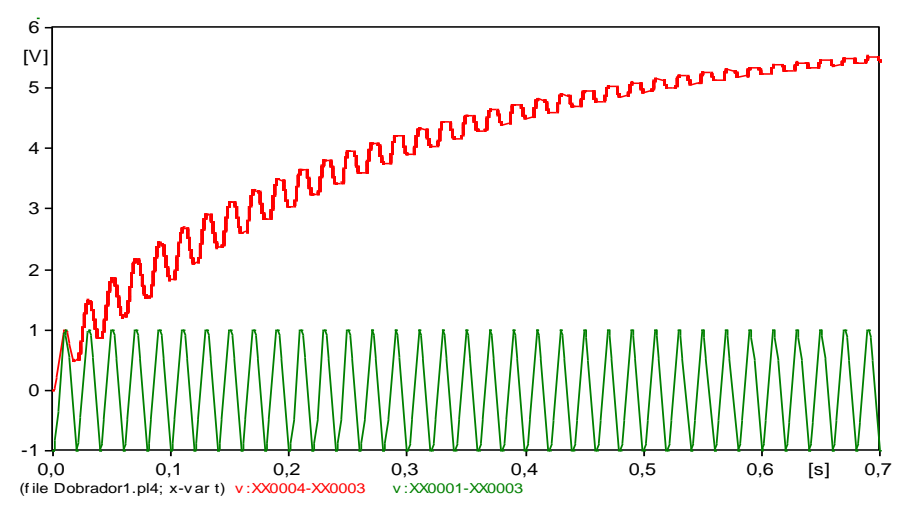

Figura 4 - Tensão de entrada e saída do multiplicador de tensão com três estágios [simulado do software Alternative Transient Program (ATP)].

A tensão de saída mostrada na Figura 4 tende ao valor de 6 pu e o baixo ripple resultante do carregamento de todos os capacitores do circuito implica uma tensão contínua (cc). Ao se estender a lógica apresentada para um circuito com um número elevado de estágios é possível obter níveis de tensões suficientemente elevados, na ordem de megavolts $\left(10^{6} \mathrm{~V}\right)$, que, quando aplicados em materiais específicos, são capazes de emitir elétrons ionizantes com energia elevada o suficiente para alterar as características físico-químicas de alguns materiais.

A alimentação do circuito gerador de tensão normalmente é feita utilizando um transformador de altas frequências, chamado de oscilador. A função principal do oscilador é elevar a frequência da rede elétrica de $60 \mathrm{~Hz}$ para valores superiores, $2.000 \mathrm{~Hz}$ por exemplo. Desse modo, as capacitâncias envolvidas no circuito multiplicador de tensão são reduzidas para se obter o mesmo valor de reatância capacitiva, ocasionando uma redução nas dimensões dos capacitores e consequentemente no custo do acelerador de elétrons. A frequência do oscilador é um parâmetro de projeto e varia para cada fabricante e para cada modelo de acelerador de elétrons.

$\mathrm{Na}$ Figura 5 é mostrado de forma simplificada o diagrama esquemático do sistema de potência elétrica do Acelerador Industrial de Elétrons RDI DC 1500/25/4 (1,5 MeV, $25 \mathrm{~mA}$ e 37,5 kW) instalado no Centro de Tecnologia das Radiações, do IPEN-CNEN/SP. Nele são apresentados os parâmetros monitorados de corrente e tensão, e os pontos onde são feitas as medidas utilizando-se osciloscópio [7]. 


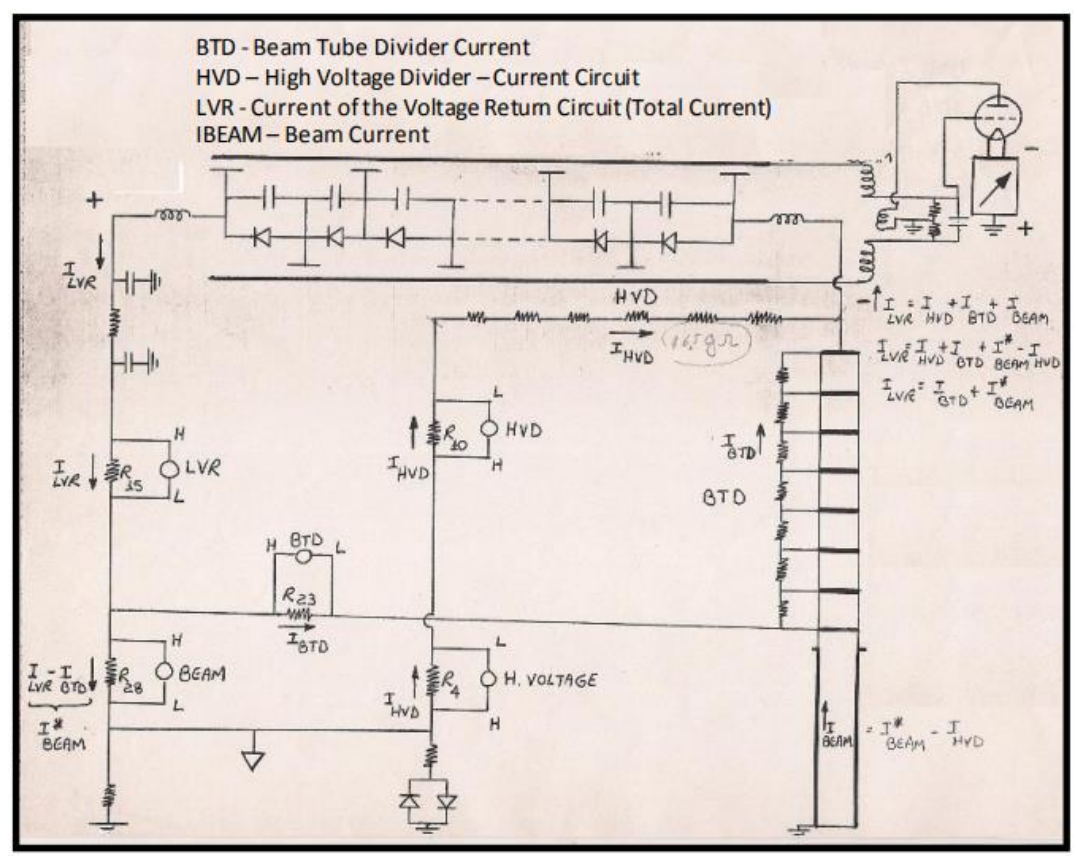

Figura 5 - Circuito de potência do Acelerador Industrial de Elétrons RDI DC 1500/25/4 (1,5 MeV, $25 \mathrm{~mA}$ e 37,5 kW) [7].

O sistema de varredura é responsável por colimar os elétrons por meio das bobinas de focalização, elétrons que, posteriormente, são defletidos através de um campo magnético oscilante que permite ajustar a faixa de largura do feixe de acordo com a necessidade. Por fim, os elétrons atravessam uma janela de titânio que separa o sistema em vácuo do material a ser irradiado. Na Figura 6 está ilustrado as partes distintas de um acelerador industrial de $500 \mathrm{keV}$ de energia de feixe.

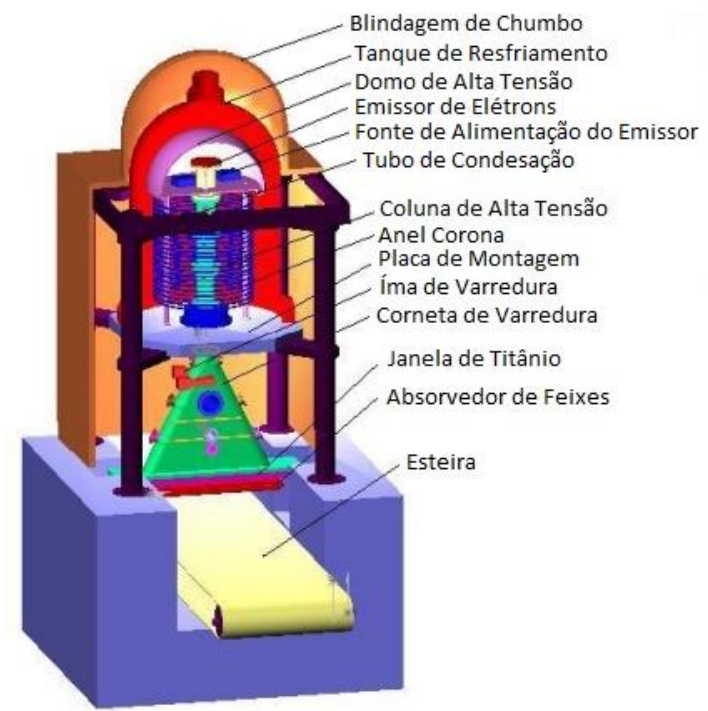

Figura 6 - Esquemático de um acelerador industrial de elétrons de $500 \mathrm{keV}\left[{ }^{8}\right]$. 


\subsubsection{Sistema de controle e proteção}

O controle dos parâmetros variáveis do acelerador de elétrons é parte essencial para monitorização da segurança operacional do equipamento. Dentre as grandezas monitoradas pode-se citar: largura de varredura do feixe de elétrons, energia e corrente do feixe, correntes e tensões do acelerador, das bombas, além do status de chaves, portas e componentes do sistema de intertravamento.

Os sensores de temperatura (usualmente do tipo termorresistências) compõem o sistema dosimétrico, responsável pelo cálculo da dose de radiação aplicada no efluente tratado com feixe de elétrons, a partir das variações de temperatura do líquido. A aplicação desse cálculo baseado na equação fundamental de calorimetria provou-se confiável em diversas aplicações, sendo a escolhida para a unidade móvel de irradiação proposta, pela sua facilidade de implementação $\left[{ }^{4}\right]$.

Os medidores de vazão são importantes para acompanhar a uniformidade das doses de radiação aplicadas ao efluente tratado. Os parâmetros elétricos do acelerador industrial de elétrons garantem o correto funcionamento do equipamento.

Os instrumentos analógicos convertem as grandezas medidas em saídas analógicas de corrente (4 a $20 \mathrm{~mA}$ ), que são enviadas para um controlador lógico programável (CLP), o qual tratará as variáveis e as disponibilizará para as telas do sistema supervisório local (SCADA).

Outro ponto importante no sistema é a segurança radiológica da instalação radiativa, dos trabalhadores e indivíduos do público envolvidos na operação da unidade móvel e nos trabalhos de tratamento de efluentes nas indústrias. A unidade móvel deverá enquadrar-se na Categoria II de aceleradores de elétrons, da norma de segurança SSG-8 Radiation Safety of Gamma, Electron and X Ray Irradiation Facilities, elaborada pela Agência Internacional de Energia Atômica (IAEA) [ $\left.{ }^{23}\right]$. A norma descreve como atender aos requisitos de segurança física e radiológica, relacionados à blindagem do sistema de irradiação e do próprio acelerador de elétrons, à qualificação dos operadores, procedimentos de emergência e monitoramento individual e local dos níveis de radiação quando em operação. Todos os intertravamentos também devem ser monitorados, por meio de sensores instalados nas portas e acessos da unidade móvel, de modo a garantir que nenhuma pessoa possa inadvertidamente se aproximar do acelerador de elétrons em funcionamento. 
Caso alguma falha seja identificada, o sistema de controle estará apto a desligar o acelerador automaticamente, cessando a emissão da radiação ionizante (feixe de elétrons e raios $\mathrm{X}$ ) no interior do bunker.

\subsubsection{Unidades móveis de irradiação}

A primeira unidade móvel de irradiação por feixe de elétrons foi desenvolvida nos Estados Unidos, na década de 90, por pesquisadores da Universidade de Miami[ [']. O acelerador projetado possuía $500 \mathrm{keV}$ de energia e $20 \mathrm{~kW}$ de potência de feixe e foi desenvolvido com auxílio da empresa High Voltage Environmental Applications Inc. $\left[{ }^{9}\right]$. A distribuição utilizada dos sistemas é mostrada na Figura 7.
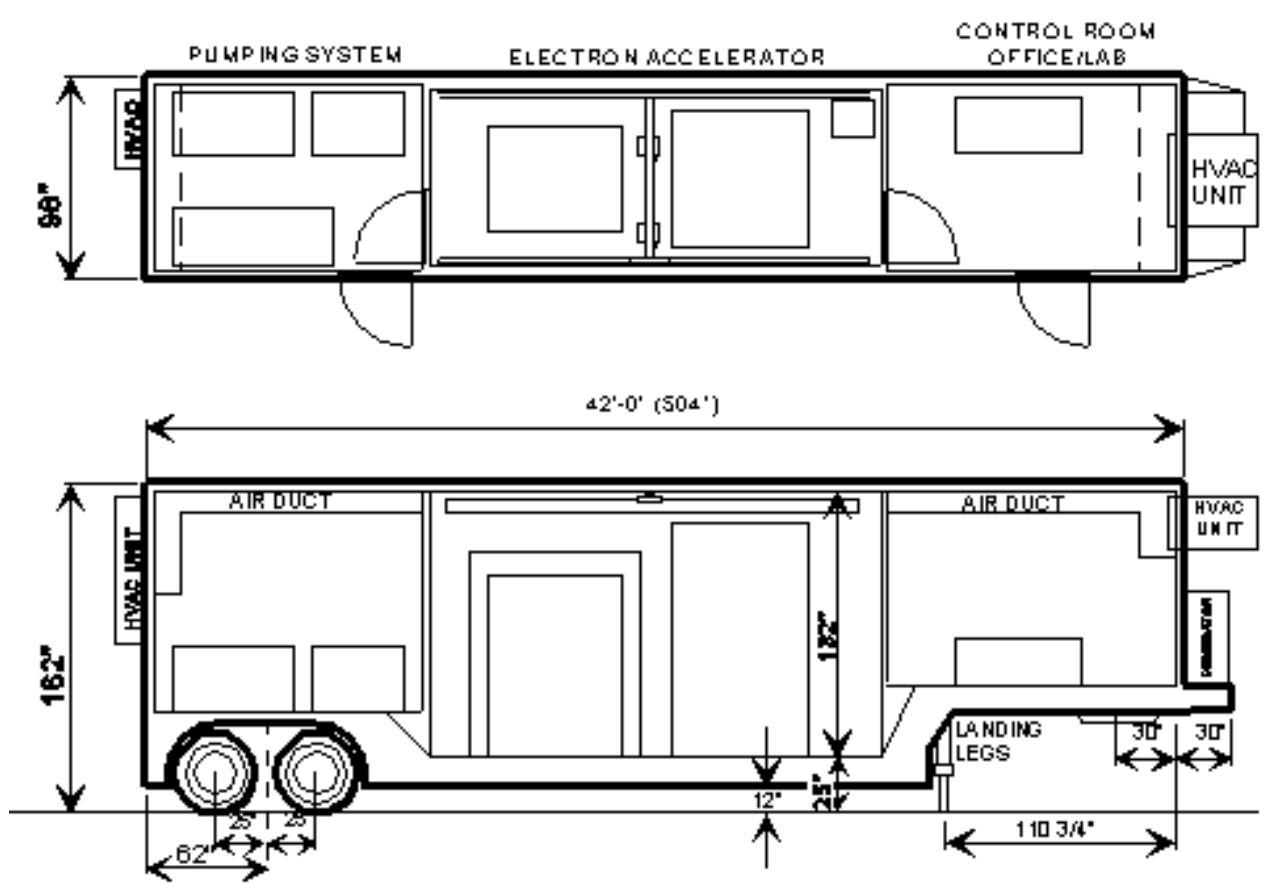

Figura 7 - Dimensional da carreta projetada pela High Voltage Environmental Applications Inc. para a unidade móvel de irradiação por feixe de elétrons da Universidade de Miami [ $\left.{ }^{9}\right]$.

Atualmente, várias empresas passaram a produzir unidades móveis de irradiação com aceleradores de elétrons, desenvolvidas para indústrias de diferentes áreas. A empresa E-ventus $\AA^{\circledR}$ atual E-Pura® está direcionada à produção e comercialização de sementes [10], além de montar e comercializar aceleradores de elétrons móveis como solução para prolongar a vida útil e qualidade das sementes 
por meio da desinfecção superficial por irradiação direta. Na Figura 8 é mostrada umas das unidades móveis produzidas e comercializadas pela empresa alemã.
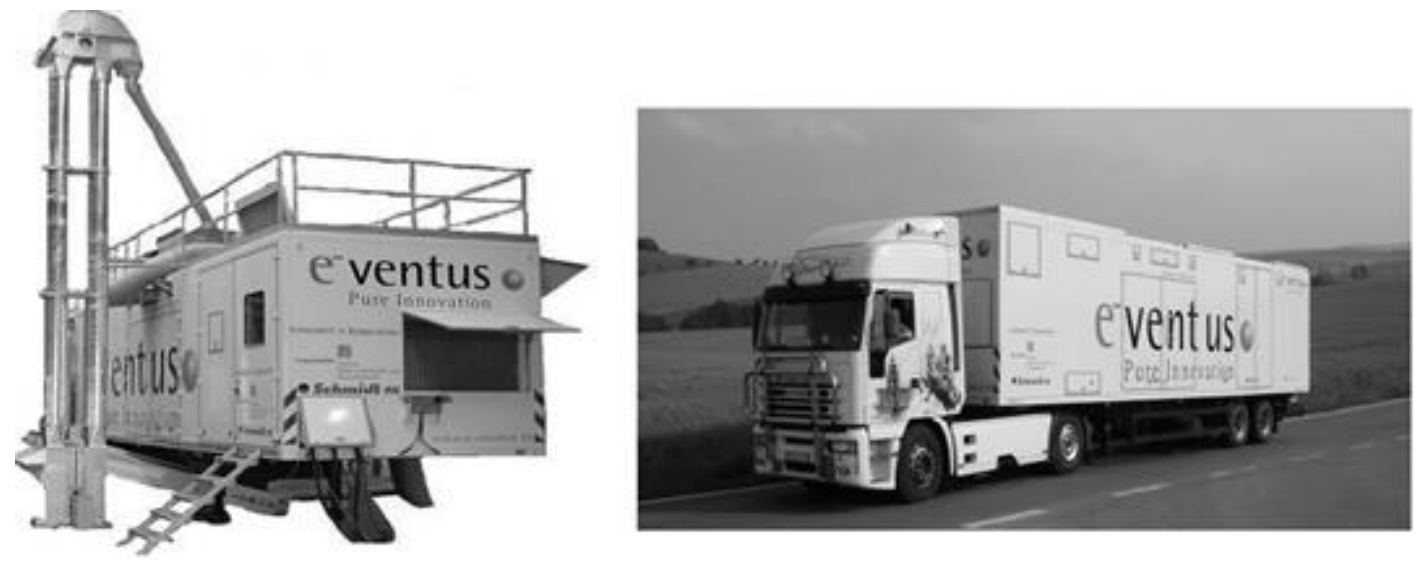

Figura 8 - Unidade móvel de irradiação por feixe de elétrons fabricada pela empresa E-ventus atual E-pura [10].

Estudos realizados anteriormente apontaram que o desenvolvimento e a construção de uma unidade móvel desse tipo são viáveis tecnicamente, respeitandose os requisitos de radioproteção e da legislação para operação vigente junto à CNEN [1]. A viabilidade econômica é inferior aos aceleradores de elétrons fixos que apresentam melhor rendimento e maior disponibilidade de operação, porém, ainda assim, é competitiva considerando os benefícios do tratamento, tais como a possibilidade de reuso das águas do efluente e a baixa emissão de gases.

No contexto geral, ainda existem poucos trabalhos específicos sobre aceleradores de elétrons industriais. $O$ estudo proposto visa ampliar o conhecimento sobre a parte de potência dos aceleradores de elétrons móveis no Brasil e no mundo, além de fornecer informações importantes para o desenvolvimento de novas unidades móveis que garantam segurança aos trabalhadores e às plantas industriais que terão seus efluentes tratados, de forma a não causar impactos no sistema elétrico e ambientais.

\section{UNIDADE MÓVEL EM DESENVOLVIMENTO PELO IPEN}

No ano de 2016, o Instituto de Pesquisas Energéticas e Nucleares (IPEN) foi contemplado com uma verba oriunda da Financiadora de Estudos e Projetos (Finep), do Ministério da Ciência e Tecnologia, Inovação e Comunicações (MCTIC) destinado ao projeto "Implantação de unidades móveis visando disponibilizar a tecnologia 
gerada no Ipen para o setor produtivo e a sociedade / troca de equipamentos obsoletos". O projeto tem por objetivo principal a aquisição de um acelerador de elétrons e desenvolvimento de uma Unidade Móvel para irradiação de resíduos sólidos, líquidos ou gasosos por feixe de elétrons.

Após financiamento da AIEA, por meio do "Projeto Nacional de Inovação BRA/1/035 - Unidade móvel de irradiação com acelerador de elétrons para tratamento de efluentes industriais para fins de reutilização" realizaram-se visitas técnicocientíficas à empresa EBTech Co., Ltd., na República da Coreia, para a especificação e o possível fornecimento do acelerador industrial de elétron, com energia de $700 \mathrm{keV}$ e potência de $20 \mathrm{~kW}$, incluindo o sistema de supervisão e controle. Com a empresa brasileira Truckvan firmou-se o acordo de cooperação técnico-científica para projetar e construir a Unidade Móvel de Irradiação, que acomodará e integrará todos os equipamentos fornecidos pelo IPEN. Os demais componentes serão desenvolvidos pelo Instituto, com o auxílio das empresas associadas.

\subsection{Acelerador de elétrons ELV-2}

O acelerador de elétrons utilizado na unidade móvel será o modelo ELV-2 produzido pelo instituto russo BINP (Budker Institute of Nuclear Physics), que desde 1971 produz e desenvolve aceleradores de elétrons desse modelo [25]. $O$ modelo consiste em um tanque cilíndrico montado na vertical, preenchido com SF6 (hexafloureto de enxofre) gás que, devido a sua rigidez dielétrica superior, permite que se tenham dimensões reduzidas para um mesmo nível de tensão se comparado ao ar. A entrada do retificador de alta tensão é composta por um oscilador que transforma a frequência da rede para $400 \mathrm{~Hz}$, seguido por um transformador com relação de espiras de 3.000, que gera uma tensão de $20 \mathrm{kVac}$. O retificador então dobra esta tensão e transforma para tensão contínua, resultando em 40 kVcc, que é utilizada pelo controlador de injeção e finalmente aplicada ao terminal de alta tensão (cátodo).

O tubo de aceleração é composto pelo filamento de alta tensão e aquecedor dispostos na extremidade de um isolador cerâmico de $180 \mathrm{~mm}$ de diâmetro interno, onde se encontram os eletrodos, espaçados de $21 \mathrm{~mm}$ entre si e energizados por pelo circuito divisor ôhmico, que consome uma corrente típica de $50 \mu \mathrm{A}$. A corrente de feixe gerada pelo circuito é controlada pela temperatura do catodo. O sistema de vácuo é 
criado por duas bombas diametralmente opostas, localizadas entre o domo de $\mathrm{SF}_{6} \mathrm{e}$ a corneta de varredura que mantém uma pressão entre $10^{-4}$ a $10^{-5}$ Pascal dentro do tubo de aceleração. Nessas condições, os elétrons podem ser acelerados até uma energia máxima de 0,7 MeV.

A corneta de varredura é magnetizada por dois eletroímãs que realizam a varredura na frequência com razão de 251/15. A corneta é resfriada por um jato de alta pressão que mantém um fluxo de ar de alta velocidade que garante que a densidade de corrente na corneta não ultrapasse o valor de $100 \mu \mathrm{A} / \mathrm{cm}^{2}$. A deflexão máxima do feixe de elétrons permitida pelo modelo adquirido é de $30^{\circ}$, que resulta em uma largura de janela de $640 \mathrm{~mm}$.

Para a potência de feixe máxima projetada de $20 \mathrm{~kW}$, o fabricante do acelerador garante uma variação máxima de $10 \%$ da densidade de corrente linear para objetos até $50 \mathrm{~mm}$ de distância que utilizem até $90 \%$ da corrente máxima de feixe [ $\left.{ }^{11}\right]$.

\subsection{Sistema de supervisão e controle}

O sistema de controle da unidade é composto por todos os hardwares e softwares necessários para o controle operativo e diagnose do acelerador de elétrons. A interface do usuário será via de mouse e teclado conectados a um computador, parte integrante do painel de controle.

Pelo software de controle é possível realizar a partida automática do acelerador, onde são verificadas as condições de partida e status dos sistemas, programar os valores desejáveis de energia e corrente de feixe e monitorar as principais grandezas medidas tais como vazão, temperatura nos componentes principais, situação das bombas e ventiladores, pressão, dose absorvida, grandezas elétricas em cada subsistema e etc. através de verificações gráficas ou menus. O software também realiza periodicamente autodiagnose do sistema (comumente chamado de watchdog) e, ao perceber qualquer anomalia no sistema de controle, automaticamente comanda o desligamento do acelerador. 


\subsection{Sistema de circulação do efluente líquido e demais equipamentos}

O sistema hidráulico da unidade será responsável pela coleta, transferência e armazenamento dos efluentes líquidos. Serão instaladas bombas de circulação com potência estimada de $15 \mathrm{~kW}$. Os fluidos serão armazenados incialmente em tanques de fibra de vidro, antes de serem processados no acelerador de elétrons, para garantir a uniformidade da vazão. Além do circuito de circulação de efluentes, devem ser previstos circuitos de circulação de ar e de resfriamento para manter a temperatura estável da sala de processos, na Unidade Móvel de Irradiação.

Outro propósito da Unidade Móvel é a divulgação da tecnologia de radiação, nas aplicações dos aceleradores de elétrons na indústria e no meio ambiente. Uma área da Unidade Móvel será destinada à sala de aula com cadeiras, mesas, projetor multimídia e microcomputadores, além de instrumentação analítica (CGMS, TOC e Cromatógrafo UV-visível), para se avaliar o efluente industrial, antes e após a irradiação. O sistema de conexão elétrica será descriminado e detalhado no capítulo a seguir.

\section{ANÁLISE DA CONEXÃO ELÉTRICA DA UNIDADE MÓVEL}

A Unidade Móvel de Irradiação será desenvolvida para se locomover por diversos pontos do Brasil e da América Latina. Portanto, deverá ser versátil para os tipos de conexão elétricas existentes, ou seja, para níveis de tensões e distâncias de conexão variáveis. Neste cenário, é necessário avaliar quais os métodos de conexões irão propiciar a maior abrangência de utilização, menor custo operacional e maior facilidade de instalação. Basicamente, serão avaliados três métodos de conexão: por baixa tensão (BT), disponível na indústria que receberá a Unidade Móvel; por média tensão (MT), disponível pela concessionária ou, em alguns casos, também pela indústria; ou por meio de geração própria pelo uso de gerador a diesel (GD), que pode ser transportado junto à Unidade Móvel.

\subsection{Conexão da média tensão}

As redes de distribuição de média tensão (MT) das concessionárias ou da própria 
indústria podem ser uma opção para alimentação da carreta. A média tensão padronizada utilizada pelas concessionárias é de $13,8 \mathrm{kV}$ ou $34,5 \mathrm{kV}\left[{ }^{12}\right.$ ], porém na indústria há uma gama bem vasta de níveis de tensão também padronizadas por norma [13].

Ao se conectar uma carga na média tensão, a corrente de consumo da unidade móvel é reduzida substancialmente em relação à conexão na baixa tensão, o que reflete na redução de perdas mesmo com grandes distâncias de conexão. Outra vantagem da média tensão é que, por possuir uma potência de curto maior, o sistema é mais robusto e menos susceptível às variações de tensão ou injeção de harmônicos, ou seja, dificilmente as demais cargas conectadas à rede de média tensão serão afetadas pela conexão da unidade móvel.

Por outro lado, para efetuar a conexão da Unidade Móvel na média tensão é necessário obter a liberação das concessionárias por meio da solicitação de acesso e ligação elétrica por funcionários credenciados $\left[{ }^{14}\right]$. Cada concessionária possui uma instrução de liberação específica, porém todas envolvem a necessidade de um responsável técnico habilitado. O desligamento da rede, quando necessário, é mais complicado por envolver diversas cargas consumidoras e os equipamentos de conexão envolvidos (cabos isolados, conectores e transformadores, dentre outros) possuem custo mais elevado em relação à baixa tensão. Outra desvantagem já mencionada é a grande variação dos níveis de tensão, o que dificulta o dimensionamento dos equipamentos.

\subsection{Geração própria}

Para locais onde os efluentes são distantes da rede elétrica ou caso a indústria não possua infraestrutura necessária para conexão da unidade móvel, a única opção disponível é através da geração própria utilizando um grupo gerador diesel.

Além da facilidade de conexão devido a não necessidade de se avaliar as condições elétricas do local, também tem como vantagem não influenciar as demais cargas da planta. $O$ gerador poderia ser transportado junto à carreta, o que facilitaria a conexão e evitaria o processo de dimensionamento, locação e transporte de uma unidade alugada.

A desvantagem principal se dá principalmente no custo de operação contínua envolvido. Para uma carga estimada de 100 kVA, o consumo médio de um gerador é 
de 21 litros por hora [15] com capacidade do tanque sendo 140 litros. Dessa forma, caso a alimentação seja exclusiva do gerador diesel, o tratamento do efluente só poderá ocorrer por aproximadamente 7 horas sem o reabastecimento do reservatório, o que inviabiliza sua operação em um modo contínuo, servindo apenas para demonstrações pontuais de curta duração.

\subsection{Conexão na baixa tensão}

A conexão na tensão de consumo quase sempre é possível devido a sua disponibilidade abrangente, porém há alguns inconvenientes como perdas devido à elevada corrente elétrica e maior queda de tensão em locais onde há grandes distâncias do ponto de conexão até a localidade onde será utilizada a unidade móvel.

Serão avaliados também os níveis de tensões praticados no território nacional, em razão da grande diversidade existente no Brasil (110/220/380/440/660 Volts). O transformador de entrada será essencial para proteger os equipamentos mais sensíveis da instalação contra surtos de tensão e para reduzir a circulação de correntes harmônicas.

Outro ponto a ser avaliado é que a conexão da carreta na baixa tensão, por estar eletricamente mais "próximo" da carga da indústria, pode ocasionar distúrbios transitórios nos processos em andamento ou até mesmo o desligamento de algum equipamento em operação durante a partida do acelerador de elétrons.

\subsection{Níveis de tensões padronizados no Brasil}

O Decreto n 41.019 de 26 de fevereiro de 1957 [12] foi o primeiro a estabelecer tensões nominais padronizadas em território nacional. Em 1988, o Art 1ํ do Decreto no $97.280\left[{ }^{16}\right]$ veio alterar as tensões nominais padronizadas de baixa tensão. Sendo assim, as tensões padronizadas vigentes estão descritas na tabela 1. 
Tabela 1 - Tensões Nominais Padronizadas no sistema elétrico nacional [16].

\begin{tabular}{|l|c|}
\hline \multicolumn{1}{|c|}{ Finalidade } & $\begin{array}{c}\text { Tensões Nominais Padronizadas } \\
\text { Transmissão e Subtransmissão }\end{array}$ \\
\hline $\begin{array}{c}750 \mathrm{kV}-500 \mathrm{kV}-230 \mathrm{kV}-138 \mathrm{kV} \\
69 \mathrm{kV}-34,5 \mathrm{kV}-13,8 \mathrm{kV}\end{array}$ \\
\hline Distribuição primária em redes públicas & $34,5 \mathrm{kV}-13,8 \mathrm{kV}$ \\
\hline Distribuição secundária em redes trifásicas públicas & $380 / 220 \mathrm{~V}-220 / 127 \mathrm{~V}$ \\
\hline Distribuição secundária em redes monofásicas públicas & $440 / 220 \mathrm{~V}-254 / 127 \mathrm{~V}$ \\
\hline
\end{tabular}

O Decreto oㅜ 97.280, no entanto, se aplica somente às vias públicas, para às indústrias não há uma norma vigente estabelecida. A norma brasileira ABNT NBR 5410 [ $\left.{ }^{17}\right]$, contudo, menciona outros níveis de tensões quando define os tempos máximos de seccionamento: 208, 230, 400, 480 e 690 Volts (fase-fase), além dos descritos na Tabela 1.

A Agência Nacional de Energia Elétrica (ANEEL) veio posteriormente, em 2013, lançar uma nota técnica (no 0153/2013-SRD/ANEEL $\left[{ }^{18}\right]$ ) na qual procurava quantificar as tensões não padronizadas e o percentual de utilização dessas. Para os consumidores de baixa tensão, o percentual de não padronização chegou a 12,76\% e para a média tensão a $36,2 \%$, segundo os dados coletados.

Esta não padronização acentuada representa um desafio no dimensionamento dos equipamentos de entrada da Unidade Móvel (transformador, cabos elétricos e disjuntores), que deverão ser escolhidos de forma a atender o maior número possível de clientes. A presença de uma tensão fora do padrão pode representar um impeditivo para a utilização da Unidade Móvel, pois os equipamentos podem não atender ao nível encontrado.

Após a ponderação dos pontos mencionados, optou-se pela escolha da conexão na baixa tensão devido à maior abrangência e maior facilidade de conexão. As tensões possíveis de utilização serão as tensões padronizadas de 220/380 Volts, além da tensão $440 \mathrm{~V}$, que foi incluída posteriormente após visitas técnicas nas Estações de Tratamento de Esgoto (ETE) da SABESP.

Além da conexão em baixa tensão, a opção da utilização do gerador a diesel ficou evidenciada após visitas técnicas em indústrias de médio porte, que poderiam receber a Unidade Móvel, uma vez que a conexão de uma carga extra da dimensão do acelerador de elétrons não é suportada pelo transformador da indústria. Nesses 
casos, a única opção será por geração própria, portanto, também será dimensionado um gerador a diesel que suporte toda a carga nominal da Unidade Móvel.

\section{DIMENSIONAMENTO DOS EQUIPAMENTOS}

\subsection{Cargas da unidade móvel}

A unidade móvel proposta engloba não somente o acelerador de elétrons propriamente dito, mas todas as cargas necessárias para o tratamento do efluente, dessa forma todas as cargas precisam ser analisadas e dimensionadas de forma que os equipamentos de entrada sejam dimensionados para a carga plena. A tabela 2 abaixo quantifica todas as cargas previstas pela carreta e seus dados básicos, tais como tensão de operação, fator de potência e demanda. Os dados foram obtidos diretamente pelos fabricantes dos equipamentos ou pelos desenvolvedores do IPEN a partir de cálculos prévios.

Tabela 2 - Cargas estimadas pertencentes a unidade móvel em desenvolvimento.

\begin{tabular}{|l|c|c|c|c|}
\hline Equipamentos & $\begin{array}{c}\text { Tensão } \\
\text { Necessária } \\
\text { (V) }\end{array}$ & $\begin{array}{c}\text { Consumo } \\
\text { Energético } \\
\text { (kW) }\end{array}$ & $\begin{array}{c}\text { Fator de } \\
\text { Potência }\end{array}$ & $\begin{array}{c}\text { Consumo } \\
\text { Total } \\
\text { (kVA) }\end{array}$ \\
\hline Acelerador de elétrons & $3 \varnothing-380$ & 30 & 0,90 & 33,33 \\
\hline $\begin{array}{l}\text { Sistema de resfriamento do } \\
\text { acelerador "chiller" }\end{array}$ & $3 \varnothing-220$ & 20,3 & 0,90 & 22,55 \\
\hline Cabine de controle & $1 \varnothing-220$ & 2 & 0,92 & 2,17 \\
\hline Bomba de vácuo (lônica) & $1 \varnothing-220$ & 2 & 0,96 & 2,09 \\
\hline $\begin{array}{l}\text { Ventilador de resfriamento da janela } \\
\text { de titânio }\end{array}$ & $3 \varnothing-380$ & 5 & 0,85 & 5,89 \\
\hline Ventilador de circulação de ar & $3 \varnothing-380$ & 5 & 0,85 & 5,89 \\
\hline $\begin{array}{l}\text { Ar condicionado, iluminação e } \\
\text { tomadas }\end{array}$ & $1 \varnothing-220$ & 5 & 0,94 & 5,31 \\
\hline $\begin{array}{l}\text { Bomba de circulação do efluente } \\
\text { líquido }\end{array}$ & $3 \varnothing-380$ & 15 & 0,89 & 16,85 \\
\hline $\begin{array}{l}\text { Microcomputador, projetor e } \\
\text { instrumentos analíticos }\end{array}$ & $1 \varnothing-220$ & 5 & 0,92 & 5,43 \\
\hline
\end{tabular}

Observação: $\varnothing=$ Fase 


\subsection{Cabos de baixa tensão}

Todos os cálculos de dimensionamento dos cabos elétricos devem seguir a norma vigente da ABNT NBR 5410 [ $\left.{ }^{17}\right]$. Nos cálculos, considerou-se de maneira conservativa a tensão de alimentação trifásica de menor valor, definida em 220/127 Volts que, por possuir as maiores correntes, resultará nas piores condições de dimensionamento. Assim, assegura-se a utilização dos cabos nas tensões de 380/220 Volts e 440/254 Volts por correlação.

\section{Método da capacidade de corrente}

A corrente nominal deve ser corrigida em seguida devido aos fatores de temperatura $(f t)$ e agrupamento $(f a)$. Para a temperatura ambiente será considerado o limite de $40^{\circ} \mathrm{C}$, pois os cabos potencialmente estarão ao ar livre e sofrendo radiação solar direta e a isolação considerada será do tipo XLPE ou EPR, portando o ft será de 0,91 segundo a tabela 40 da NBR 5410 [17]. O fator fa é determinado pelo número de circuitos totais. No presente caso, será considerado somente um circuito que resulta no fator unitário segundo a tabela 42 da mesma norma. O dimensionamento dos cabos de alimentação da unidade móvel, portanto, será dado pelas Equações 1,2 e 3:

$$
\begin{aligned}
& P_{\text {TOT }}=\sum P_{3 \phi}+\sum P_{1 \phi}=99,51 \mathrm{kVA} \\
& I n=\frac{P_{\text {TOT }}}{V_{L L} \cdot \sqrt{3}}=\frac{93810}{220 \cdot \sqrt{3}}=261,14 \mathrm{~A} \\
& I c=\frac{I n}{f t \times f a}=\frac{246,16}{0,91 \cdot 1}=286,98 \mathrm{~A}
\end{aligned}
$$

Nas quais, $P_{\text {тот }}$ é a potência nominal total do sistema

$P_{3 \varphi}$ e $P_{1 \varphi}$ são as potências nominais trifásicas e monofásicas das cargas

In é a corrente nominal do sistema

$V_{L L}$ é a tensão de linha do sistema

$I_{\mathrm{C}}$ é a corrente nominal corrigida

$f t$ é o fator de correção por temperatura conforme tabela 40 da NBR 5410:2004

$f a$ é o fator de correção para agrupamento de circuitos conforme tabela 42 da NBR 5410:2004 
O método de referência a ser adotado depende do tipo de instalação a ser utilizada. No caso da unidade móvel é sugerido que o cabo seja tripolar, para facilitar a conexão, instalado diretamente sobre o solo através de somente um circuito. Deste modo é obtido o método $\mathrm{C}$ segundo a NBR 5410 [ $\left.{ }^{17}\right]$. Na tabela 37 da mesma norma são demonstradas as capacidades de correntes máximas para as secções nominais variáveis. Para suportar a corrente corrigida de 287 A, o cabo tripolar de $120 \mathrm{~mm}^{2}$ atenderia por permitir corrente de até 322 A, portanto a mínima bitola permitida por este critério é de $120 \mathrm{~mm}^{2}$.

\section{Proteção Contra Curto Circuito}

Os cabos de entrada devem ser capazes de suportar o curto-circuito até o momento de abertura do disjuntor eletricamente a montante pela proteção. No caso da unidade móvel, o nível de curto varia, pois irá depender de cada local onde será instalada. Os valores de capacidade de interrupção dos disjuntores usualmente variam de $25 \mathrm{kA}$ a $100 \mathrm{kA}$ na tensão de $440 \mathrm{~V}$. Os valores mais elevados normalmente são encontrados em locais onde há conexões próximas a linhas de alta tensão ou próximos a pontos de geração, que dificilmente será o caso da unidade móvel, portanto será considerado para base no cálculo o nível de 50 kA. O tempo de retirada do curto pela proteção também irá depender do ajuste ou curva do disjuntor da indústria, como este valor é desconhecido, será verificado qual o tempo mínimo que a ser obtido com a bitola proposta e analisado se este atende aos tempos mínimos necessários.

O cálculo segundo a NBR para curtos-circuitos simétricos, ou com baixa assimetria $(X / R)$, é dado pela Equação 4:

$$
I^{2} \cdot t \leq k^{2} \cdot S^{2}
$$

Na qual, I: Corrente de curto-circuito simétrica máxima;

$t$ : Duração do curto-circuito;

$k$ : Fator de correção dependente da isolação do cabo;

$S$ : Seção do cabo em milímetros quadrados.

Considerando o valor de k em 143 obtido pela tabela 30 da norma e rearranjando os termos, obtém-se a Equação 5 a seguir: 


$$
t \leq \frac{(143)^{2} \cdot(120)^{2}}{(50.000)^{2}}=0,117 \mathrm{~s}
$$

Portanto, para a condição estabelecida, o cabo de $120 \mathrm{~mm}^{2}$ suportaria o curto sem danos caso sua duração fosse inferior a $117 \mathrm{~ms}$. Este valor calculado é aceitável, considerando o tempo de processamento e identificação do dispositivo de proteção, tempo de atuação da bobina de abertura e tempo de abertura mecânica do disjuntor. Usualmente os fabricantes adotam o tempo máximo de abertura sendo $50 \mathrm{~ms}$, portanto o tempo calculado é suficiente para a identificação da falta e abertura do disjuntor de forma a não danificar o cabo em questão para o nível de curto circuito estipulado.

\section{Método de Queda de Tensão}

Como a distância da unidade móvel ao barramento de baixa tensão irá variar em cada local, será verificado o comprimento máximo dos cabos de modo a atender a queda de tensão máxima imposta pela norma técnica NBR 5410 de 4\% para cargas alimentadas diretamente por um ramal de baixa tensão. A queda de tensão imposta pelo circuito em questão depende da corrente nominal, das impedâncias dos cabos e da distância total do circuito. Sendo assim, na Equação 6:

$$
\Delta V \%=\frac{173,2 \cdot L \cdot \rho \cdot I}{S \cdot V}
$$

Na qual, $\Delta \mathrm{V} \%$ : Queda de tensão admissível (\%);

L: distância total do circuito (m);

$\rho$ : resistividade do material corrigida (alumínio ou cobre) $\left(\Omega . \mathrm{mm}^{2} / \mathrm{m}\right.$ );

V: tensão nominal de linha (V);

I: corrente nominal (A)

S: Seção do condutor $\left(\mathrm{mm}^{2}\right)$

A resistividade a ser utilizada deve ser corrigida para temperatura ambiente pela fórmula descrita na Equação 7:

$$
\rho=\rho_{0} \cdot\left[1+\alpha\left(T_{F}-T_{a}\right)\right]
$$

Na qual, $\rho:$ resistividade do cobre corrigida $\left(\Omega . \mathrm{mm}^{2} / \mathrm{m}\right)$; 
$\rho_{0}$ : resistividade do cobre $\left(\Omega . \mathrm{mm}^{2} / \mathrm{m}\right)$;

$\alpha:$ Coeficiente de temperatura;

$\mathrm{T}_{\mathrm{F}}$ : Temperatura final $\left(\mathrm{C}^{\mathrm{o}}\right)$;

$\mathrm{T}_{\mathrm{a}}$ : Temperatura ambiente $\left(\mathrm{C}^{\mathrm{o}}\right)$.

Para o caso com condutores de cobre em $40^{\circ}$ encontra-se, via Equação 7 :

$$
\rho=0,017[1+0,0039(40-20)]=0,0183 \Omega \cdot \mathrm{mm}^{2} / \mathrm{m}
$$

Sendo assim, o comprimento máximo permitido para os cabos de média tensão em 220 V será obtido rearranjando-se a Equação 6 e utilizando a queda máxima de 4\%:

$$
L=\frac{\Delta V \% \cdot S e c ̧ \tilde{a} o \cdot V}{173,2 \cdot \rho \cdot I}=\frac{4 \cdot 120 \cdot 220}{173,2 \cdot 0,0183 \cdot 261,1}=127 \mathrm{~m}
$$

Portanto, a distância máxima da carreta até o ponto de conexão elétrica é de $127 \mathrm{~m}$ para os cabos estipulados de $120 \mathrm{~mm}^{2}$. Pelas visitas realizadas nas industrias, concluiu-se que a distância de 100 metros já seria suficiente para a conexão, portanto a distância estimada de 100 metros atende ao critério de queda de tensão por ser inferior a distância máxima calculada. Caso a distância de conexão seja superior à máxima calculada, será necessário utilizar cabos com seções superiores para atender este critério.

\section{Secção Mínima}

A norma também define as seções mínimas dos condutores dependendo da aplicação do circuito. Para condutores de cobre, não é admitido secções inferiores a 2,5 $\mathrm{mm}^{2}$ para circuitos de força. Como os métodos antecedentes exigem seções superiores, este critério de dimensionamento é atendido consequentemente.

\section{Material e Classe da Isolação}

A tensão de isolação sugerida para os cabos em questão é $0,6 / 1 \mathrm{kV}$, que garante a suportabilidade perante a faltas fase-terra, mesmo para sistemas isolados. Para o material da isolação, existem duas tecnologias principais utilizadas pelo mercado, baseadas em polietileno (PE) ou propileno (EPR). A isolação XLPE 
(polietileno reticulado) é suscetível ao efeito treeing, fenômeno causado pela penetração de moléculas de água na isolação. O efeito treeing provoca danos à isolação o e reduz a vida útil da mesma. A isolação EPR (borracha de etileno propileno) é resistente a esse efeito e, por isso, apresenta vida útil levemente superior. Além disso, alguns tipos de EPR são mais resistentes ao calor, podendo trabalhar com temperaturas contínuas de até $105^{\circ} \mathrm{C}$. Para a utilização da unidade móvel, como os cabos potencialmente ficarão expostos ao tempo e a intempéries, é sugerida a utilização da isolação em EPR. A Tabela 3 ilustra as características básicas sugeridas para aquisição do cabo de entrada.

\section{Dimensionamento Cabo de Proteção}

Como não haverá uma malha de terra específica para a unidade móvel, é imprescindível que se conecte a mesma ao sistema de aterramento da indústria através de um cabo de aterramento próprio. Sua função será além da equipotencialização da unidade móvel, garantir a proteção contra choques elétricos. Para dimensionamento deste, denominado de PE, a norma estabelece a mesma fórmula utilizada no critério de curto-circuito. Para o tempo de abertura será considerado 50 ms que é o tempo usual de abertura dos disjuntores, para o nível de curto-circuito a ser considerado, apesar de no ponto de conexão o nível ser reduzido justamente pela impedância do cabo, será considerado os 50 kA inicias. Desta forma, a seção mínima do condutor é dada conforme Equação 6:

$$
S \geq \frac{\sqrt{I^{2} \cdot t}}{k}=\frac{\sqrt{(50.000)^{2} \cdot 0,050}}{176}=63,52 \mathrm{~mm}^{2}
$$

O fator $k$ é determinado pela tabela 53 da NBR 5410.

A norma menciona outro método de dimensionamento citado na Tabela 58, baseado na seção do cabo condutor. Nesse método, recomenda-se que a seção do cabo de proteção seja a metade da seção do cabo condutor, desta forma a seção seria de $60 \mathrm{~mm}^{2}$. O valor sugerido, portanto, considerando os dois métodos será de $70 \mathrm{~mm}^{2}$ de seção.

A Tabela 3 a seguir resume os dados sugeridos para os cabos de entrada. 
Tabela 3 - Características sugeridas dos cabos de entrada da unidade móvel.

\begin{tabular}{|c|c|c|c|c|c|c|}
\hline \multirow[b]{2}{*}{ Aplicação } & \multicolumn{2}{|c|}{ Condutor } & \multirow[b]{2}{*}{$\begin{array}{c}\text { Comprimento } \\
\text { Total }(\mathrm{m})\end{array}$} & \multirow[b]{2}{*}{ Encordoamento } & \multicolumn{2}{|c|}{ Isolação } \\
\hline & Material & $\begin{array}{c}\text { Secção } \\
\left(\mathrm{mm}^{2}\right)\end{array}$ & & & Tipo & $\begin{array}{c}\text { Classe } \\
(\mathrm{kV})\end{array}$ \\
\hline Fase & Cobre & Tripolar 120 & 100 & Classe IV ou V & EPR 90 & $0,6 / 1$ \\
\hline Proteção & Cobre & Singelo 70 & 100 & Classe IV ou V & EPR 90 & - \\
\hline
\end{tabular}

\subsection{Disjuntor de entrada}

O disjuntor de entrada sugerido será do tipo caixa moldada com disparador eletrônico LSI (long/short/instantaneous) ajustável, que permitirá maior flexibilidade de operação. A corrente de disparo por sobrecarga deverá ser ajustável tanto para a corrente máxima (obtida com a tensão de $220 \mathrm{~V}$ ) quanto para a corrente mínima (tensão de entrada em $440 \mathrm{~V}$ ). A utilização de disparador eletrônico permite maior facilidade da coordenação e seletividade com os demais dispositivos da indústria a ser conectada à unidade móvel. Não é recomendado que este disjuntor tenha comando remoto por se tratar de uma manobra que deve ser realizada por profissional habilitado e somente uma vez por deslocamento da unidade móvel.

A capacidade de interrupção de corrente simétrica suportável pelo disjuntor deve estar em consonância com a corrente de curto trifásica máxima do sistema em que a carreta está conectada. O nível considerado no dimensionamento dos cabos foi de $50 \mathrm{kA}$, porém este valor será reduzido significativamente devido à presença da impedância do cabo de alimentação, é sugerida a utilização de disjuntores de $36 \mathrm{kA}$, que devem ser capazes de abranger a maioria dos barramentos de $440 \mathrm{~V}$ existentes, o que não exime uma verificação prévia dos níveis de curto-circuito em cada instalação da unidade móvel. O valor considerado será validado posteriormente durante a modelagem do sistema utilizando softwares computacionais.

\subsection{Transformador isolador}

O transformador na Unidade Móvel será importante por diversos motivos dentre eles, isolar o circuito contra surtos de tensão, possibilitar a conexão para diversos níveis de tensão, reduzir o nível de curto no quadro de distribuição e reduzir a 
influência dos harmônicos na rede externa.

Como a tensão de entrada não é um elemento claramente definido em razão da variedade de níveis de tensões existentes, o transformador deverá ser projetado com TAP's em derivação no enrolamento primário de modo a permitir diversos níveis de tensão, enquanto o enrolamento secundário de tensão fixa mantida em $380 \mathrm{~V}$ para o acelerador de elétrons e motores, e em $220 \mathrm{~V}$ para o Chiller e demais equipamentos e componentes.

Os transformadores em geral são dimensionados para cargas lineares e classe de temperatura $F\left(155 C^{\circ}\right.$ ). Na presença de cargas não lineares, há um aumento das perdas no transformador por efeito Joule e perdas no ferro em função ao aparecimento de correntes harmônicas.

O parâmetro que determina a suportabilidade de transformadores perante conteúdos harmônicos é o fator K definido pelas normas UL 1561-1994 e UL 15621994 conforme guia IEEE C57.110 [ $\left.{ }^{19}\right]$. Um fator K unitário indica que o transformador está dimensionado para suportar apenas cargas lineares.

O fator $\mathrm{K}$ é definido conforme Equação 8 abaixo:

$$
\text { Fator } K=\sum_{h=1}^{\infty}\left(\frac{I_{h}}{I_{R}}\right)^{2} h^{2}
$$

Na qual a variável $h$ representa a ordem harmônica, $I_{h}$ a corrente harmônica e Ir a corrente total.

A taxa de distorção harmônica do acelerador de elétrons da Unidade Móvel é desconhecida e não informada pelo fabricante; portanto, para o dimensionamento do transformador deve ser considerado um percentual estimado. No caso do acelerador que é a principal fonte harmônica, serão utilizados os percentuais de distorção medidos no acelerador RDI disponível no Centro de Tecnologia das Radiações do IPEN, trabalhando-se nas mesmas condições de energia de elétron e corrente de feixe próxima. Conforme será demonstrado em capítulo específico, o índice de distorção harmônica total medido para o acelerador foi de $\mathrm{K}=7,28$.

Como o cálculo é baseado no percentual total das cargas, e o acelerador de elétrons da unidade móvel representa apenas um terço das cargas totais, esse fator é reduzido para $\mathrm{K}=1,61$ ao se realizar novamente a somatória da equação 8, considerando todos os demais componentes, ou seja, a corrente total da Unidade Móvel em operação plena. 
Devido ao baixo valor encontrado é sugerido, por questões econômicas, adquirir um transformador com fator $\mathrm{K}$ unitário, porém sobre dimensionado, levandose em conta as perdas extras decorrentes das correntes harmônicas. Este conceito, denominado derating [ $\left.{ }^{20}\right]$, é normatizado e considerado também pela IEEE [ $\left.{ }^{19}\right]$. Seu cálculo depende das perdas de magnetização do núcleo do transformador, conforme Equação 9.

$$
I_{M A X}(p u)=\left[\frac{1+P_{E C-R}(p u)}{1+(K) \cdot P_{E C-R}(p u)}\right]^{1 / 2}
$$

Na qual, $P_{E C-R}(p u)$ são as perdas por correntes parasitas, ou correntes de Foucault, em condições nominais e $\mathrm{K}$ o fator das harmônicas.

O valor das perdas por correntes parasitas depende diretamente dos dados de projeto do transformador, usualmente é possível obtê-los analisando os dados de placa do fabricante. Para um transformador de $100 \mathrm{kVA}$, o valor usual informado por um fabricante consultado é de $500 \mathrm{~W}$ de perdas a vazio e de $2.900 \mathrm{~W}$ perdas totais. Desta maneira o valor de $P_{E C-R}(p u)$ resulta da relação entre os dois valores, ou 0,17pu. Desta maneira a equação 13 é resolvida:

$$
I_{M A X}(p u)=\left[\frac{1+0,17}{1+(1,61 \cdot 0,17)}\right]^{\frac{1}{2}}=0,95
$$

O valor calculado indica que a corrente real suportável é inferior ao valor nominal de placa. Portanto, suprir 100 kVA de carga considerando o conteúdo harmônico do acelerador de elétrons será necessário um valor superior conforme a Equação 10:

$$
P_{\text {TOT }}=\frac{P_{\text {CONSUMO }}}{I_{M A X}(p u)}=\frac{100 k v a}{0,95}=105,2 \mathrm{kVA}
$$

Desta maneira, o transformador deverá possuir potência nominal superior a 105,2 kVA para suportar continuamente todas as cargas elétricas da Unidade Móvel considerando a distorção harmônica produzida pelo acelerador.

\subsection{Gerador a diesel}

Considerando as mesmas premissas adotadas previamente, o gerador diesel deverá ser dimensionado para atender a carga nominal levando-se em consideração o conteúdo harmônico estipulado. Conforme já explicado seu uso deverá ser restrito 
a locais onde não será possível a conexão elétrica. Quando em operação, não é recomendado o uso contínuo do gerador devido aos altos gastos envolvidos, apenas a realização de tratamento pontual dos efluentes para quesitos demonstrativos. Considerando a premissa de não operação em regime contínuo, o gerador posse ser dimensionado para a potência "standby" mínima de 110 kVA, ou seja, possui uma característica limitada de tempo de operação na potência nominal.

Como não é possível determinar as condições de abrigo do gerador, será necessária a carenagem de proteção contra intempéries. Foi analisado com base em modelos padrões, se seria possível transportar o gerador diesel dentro a carreta, porém por questões de limites de peso sobre eixos, esta opção não foi viabilizada. 0 sistema de controle da unidade geradora deverá será apenas localmente, e partida manual por um operador. O motor sugerido é do tipo estacionário e com alternador brushless autoventilado.

Outra recomendação importante que se deve ter precaução é com relação as correntes de partida. Como a Unidade Móvel possui diversas cargas elétricas com elevadas correntes de partida como as bombas, é importante que não seja acionado o gerador com todas as cargas já ligadas, assim os esforços transitórios de partida no gerador serão reduzidos e sua vida útil não será tão afetada.

\section{MODELAGEM ELÉTRICA DO SISTEMA MÓVEL}

O sistema elétrico da Unidade Móvel foi modelado considerando todas as cargas e equipamentos descritos em funcionamento pleno, mostrado na Tabela 1. 0 software utilizado para a modelagem dos equipamentos e análise das grandezas elétricas é o Power System Software (PTW), da fabricante SKM System Analysis, Inc. O software permite o cálculo das correntes de curto-circuito, validação dos disjuntores, verificação gráfica da seletividade dos ajustes de corrente e verificação dos índices de distorções harmônicas.

A potência de curto-circuito no ponto de conexão é um dado que não se pode determinar, eis que irá variar de local em local. Para realizar uma análise abrangente, considerou-se que a potência de curto no ponto de conexão é a mesma do nível de curto dos equipamentos e barramentos da Unidade Móvel, de $50 \mathrm{kA}$ com um X/R típico de 15. Assim, serão avaliadas as condições no caso mais severo, porém ainda 
suportável pela Unidade Móvel. Esses valores considerados são importantes somente para o dimensionamento do cabo e do disjuntor de entrada. Para os demais equipamentos, a corrente de curto-circuito será limitada pelo transformador de entrada da Unidade Móvel, portanto não dependem da corrente de curto do ponto de conexão.

O cabo elétrico em cobre de entrada foi considerado conforme o proposto, ou seja, 120 mm², 100 metros de comprimento, isolação EPR, de 3 fios condutores mais o de proteção. O disjuntor de entrada considerado possui a característica de proteção LSI (long/short/instantaneous), o que significa que é possível ajustar valores de desligamento (trip) para sobrecarga (tempos longos de atuação) para transitórios (tempos pequenos de atuação) e para curtos-circuitos (tempos instantâneos de atuação). Os demais disjuntores do circuito serão considerados disjuntores termomagnéticos fixos, cada um com a curva dependendo da aplicação e da corrente nominal.

Para o transformador de potência da Unidade Móvel foi considerado o modelo típico de um transformador a seco 112,5 kVA, ligado em delta no primário e estrela aterrado no secundário (lado da carga). Esta ligação se deve ao fato que alguns equipamentos da Unidade Móvel possuem tensão nominal de 220 V, sendo, portanto, necessária a ligação em estrela no secundário.

As bombas foram consideradas como motores de indução, fator de potência e eficiência de acordo com os dados de tabela dos fabricantes. O acelerador de elétrons foi modelado como uma carga constante de $33 \mathrm{kVA}$, porém com um alto índice de contribuição harmônica. A figura 9 ilustra o diagrama unifilar proposto para a unidade móvel.

\subsection{Níveis de curto-circuito}

As simulações de curto-circuito foram executadas considerando diversos cenários distintos, variando-se a potência de curto-circuito no ponto de conexão, bem como a distância de conexão e bitola do cabo. Os resultados mostrados na Figura 10 ilustram o cenário mais provável, com cabo dimensionado de $120 \mathrm{~mm}^{2}$, com 100 metros de comprimento e nível de curto no ponto de conexão de 50 kA. 


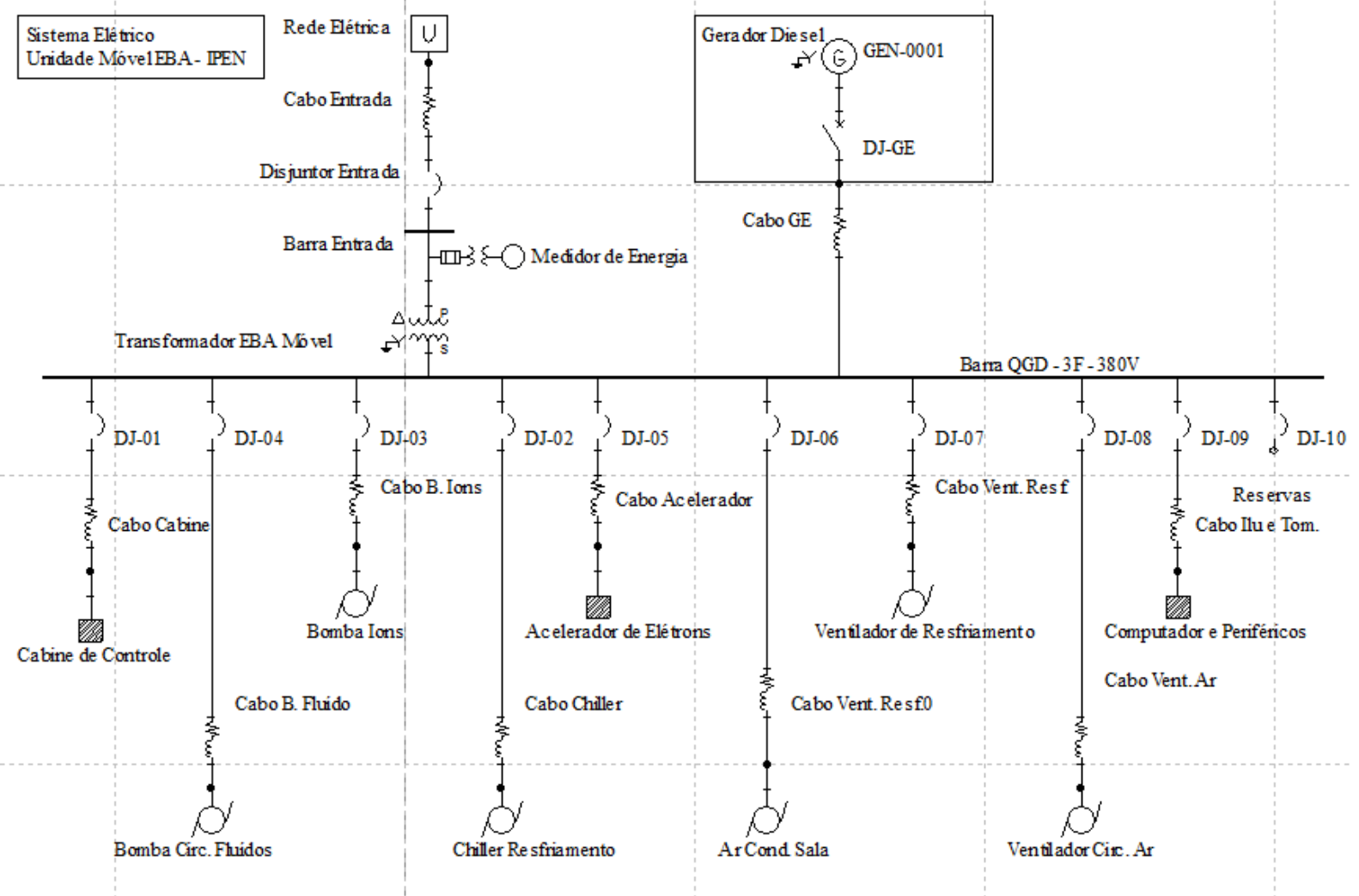

Figura 9 - Diagrama unifilar da unidade móvel proposta (software PTW).

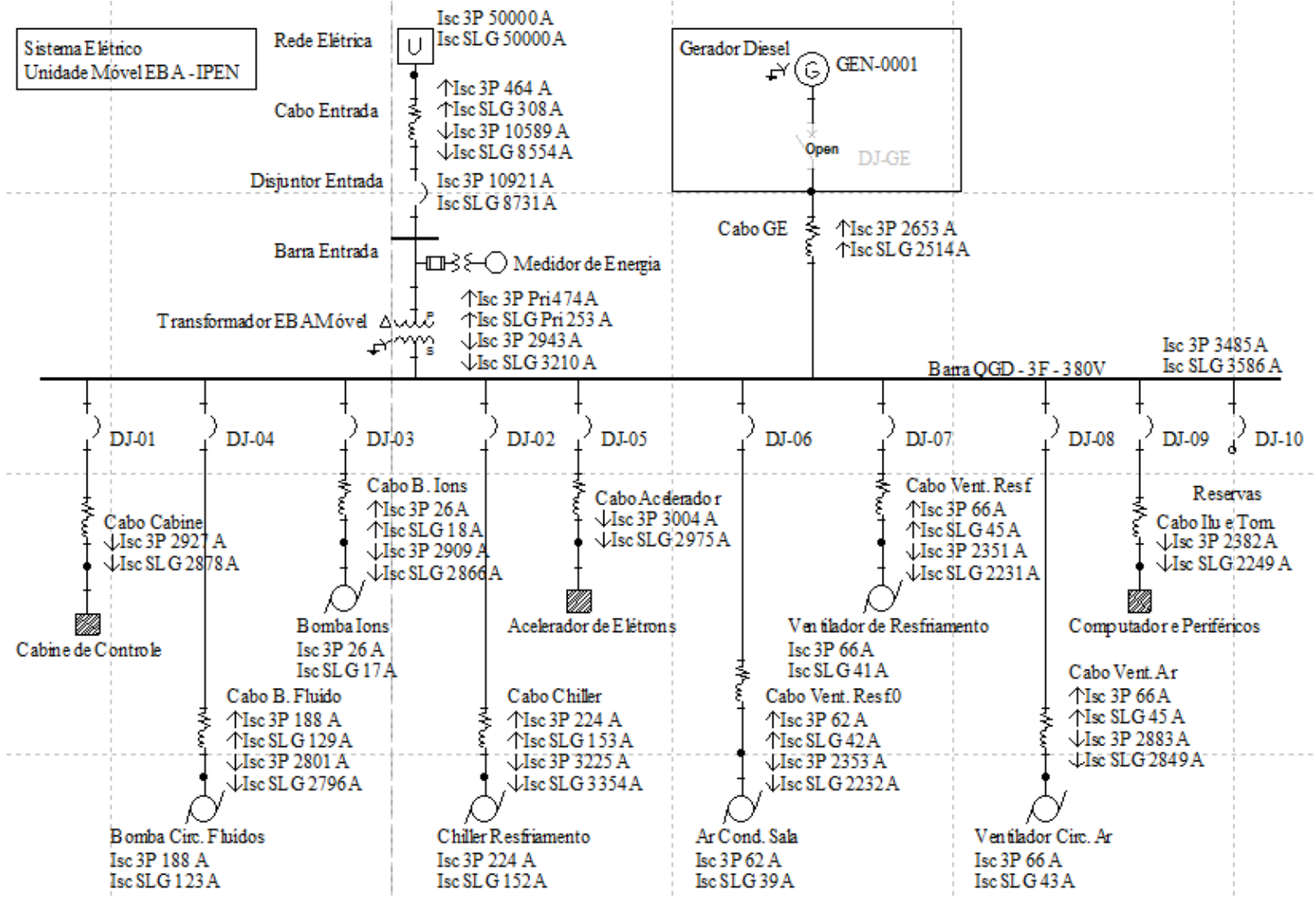

Figura 10 - Níveis de curtos-circuitos nos barramentos e contribuição de cada trecho para o curto (software PTW). 
As simulações indicaram o comportamento esperado, o curto-circuito na barra entre o disjuntor de entrada e o transformador depende diretamente da potência de curto do sistema e do comprimento do cabo de entrada. O valor encontrado na simulação foi de aproximadamente $12 \mathrm{kA}$ para um curto trifásico, valor este inferior aos $36 \mathrm{kA}$ de capacidade de interrupção do disjuntor. Outro ponto interessante a ressaltar é que, considerando a rede como um modelo de barra infinita (potência de curto-infinita), o curto no disjuntor seria o mesmo, pois estaria limitado pela impedância do cabo de 100 metros. Nesse caso, um cabo de até 30 metros garantiria a limitação do curto até o limite suportável de $36 \mathrm{kA}$. Apesar de o nível de curto nas condições padrão estar abaixo da capacidade do disjuntor, é sugerido manter as características do disjuntor justamente no caso de utilização de outros cabos.

$\mathrm{O}$ valor de curto-circuito na barra $380 \mathrm{~V}$ do quadro de distribuição é sempre limitado pelo transformador de 112,5 kVA. A contribuição total obtida, considerando inclusive a contribuição dos motores, foi de aproximadamente 3,6 kA fase-terra. Esse valor pode parecer baixo à primeira vista, porém é necessário ficar atento, pois a grande parte dos fabricantes de disjuntores de baixa tensão comercializam seus disjuntores com capacidade de interrupção de $3 \mathrm{kA}$, de menor custo, portanto, para a Unidade Móvel. Porém, devem ser escolhidos disjuntores com capacidade igual ou superior a $5 \mathrm{kA}$.

\subsection{Coordenação e seletividade}

O objetivo principal da coordenação e seletividade é propiciar que, durante uma falta, apenas o trecho defeituoso seja desligado não afetando os circuitos adjacentes. Para a Unidade Móvel, os disjuntores específicos de cada equipamento devem ser coordenados somente com o disjuntor de entrada, o que é facilmente obtido ao se ajustar uma corrente de atuação superior no disjuntor de entrada. Também é necessário cuidado para não se utilizar disjuntores que possuam curvas muito inversas para os motores, pois podem ser sensibilizados nas partidas dos mesmos.

A grande dificuldade desse item será em relação à coordenação dos disjuntores no barramento elétrico da indústria, no qual será conectada a Unidade Móvel. Como será acrescentada uma carga extra de 112,5 kVA ao sistema elétrico da indústria, é possível a ocorrência de alguma atuação indevida de proteção térmica 
(sobrecarga) do disjuntor a montante da indústria, podendo desligar indevidamente todas as cargas dessa barra. Mais uma vez se torna necessária a análise preliminar do sistema elétrico local por um engenheiro antes da conexão da Unidade Móvel.

Os disjuntores específicos de cada carga foram dimensionados pela corrente nominal e pela aplicação. As cargas com motores foram dimensionadas com a curva C, para evitar a atuação indevida durante a partida, enquanto os demais equipamentos, com a curva B. Na Tabela 4 apresentam-se as características escolhidas para os disjuntores do quadro de distribuição elétrica.

Tabela 4 - Características sugeridas para os disjuntores do quadro de distribuição.

\begin{tabular}{|l|c|c|c|c|c|}
\hline Equipamento & TAG & $\begin{array}{c}\text { No } \\
\text { Polos }\end{array}$ & $\begin{array}{c}\text { Corrente } \\
\text { Nominal } \\
(\mathbf{A})\end{array}$ & $\begin{array}{c}\text { Disjuntor } \\
\text { (A) }\end{array}$ & Curva \\
\hline Painel de controle & $52-01$ & 1 & 5,2 & 8 & $\mathrm{~B}$ \\
\hline $\begin{array}{l}\text { Bomba de circulação do } \\
\text { efluente líquido }\end{array}$ & $52-02$ & 3 & 22,8 & 40 & $\mathrm{C}$ \\
\hline Bomba de vácuo (iônica) & $52-03$ & 1 & 5,2 & 8 & $\mathrm{C}$ \\
\hline $\begin{array}{l}\text { Sistema de resfriamento do } \\
\text { acelerador (chiller) }\end{array}$ & $52-04$ & 1 & 34,2 & 63 & $\mathrm{C}$ \\
\hline Acelerador de elétrons & $52-05$ & 3 & 45 & 63 & $\mathrm{C}$ \\
\hline $\begin{array}{l}\text { Ar condicionado, iluminação e } \\
\text { tomadas }\end{array}$ & $52-06$ & 1 & 13,2 & 16 & $\mathrm{C}$ \\
\hline $\begin{array}{l}\text { Ventilador de resfriamento da } \\
\text { janela de titânio do acelerador }\end{array}$ & $52-07$ & 3 & 7,6 & 10 & $\mathrm{C}$ \\
\hline $\begin{array}{l}\text { Ventilador para circulação de } \\
\text { ar }\end{array}$ & $52-08$ & 3 & 7,6 & 10 & $\mathrm{C}$ \\
\hline $\begin{array}{l}\text { Microcomputador, projetor e } \\
\text { instrumentos analíticos }\end{array}$ & $52-09$ & 1 & 13,2 & 16 & $\mathrm{~B}$ \\
\hline Reserva & $52-10$ & 1 & 13,2 & 8 & $\mathrm{~B}$ \\
\hline
\end{tabular}

Os disjuntores e as curvas definidas anteriormente foram confirmados através de análise gráfica do coordenograma dos dispositivos de proteção envolvidos. Os ajustes do disjuntor de entrada também foram obtidos através da análise de gráfica de modo a não permitir a atuação da proteção durante a energização do transformador, e de modo a proteger o transformador para faltas que possam danificálo. A figura 11 abaixo ilustra o coordenograma do trecho que engloba o acelerador de elétrons até a conexão externa com a indústria e a figura 12 ilustra o trecho que engloba a bomba de circulação de fluido até a conexão externa. $O$ transformador foi simulado com a configuração de $380 \mathrm{~V}$ de tensão de entrada. 
CURRENT IN AMPERES

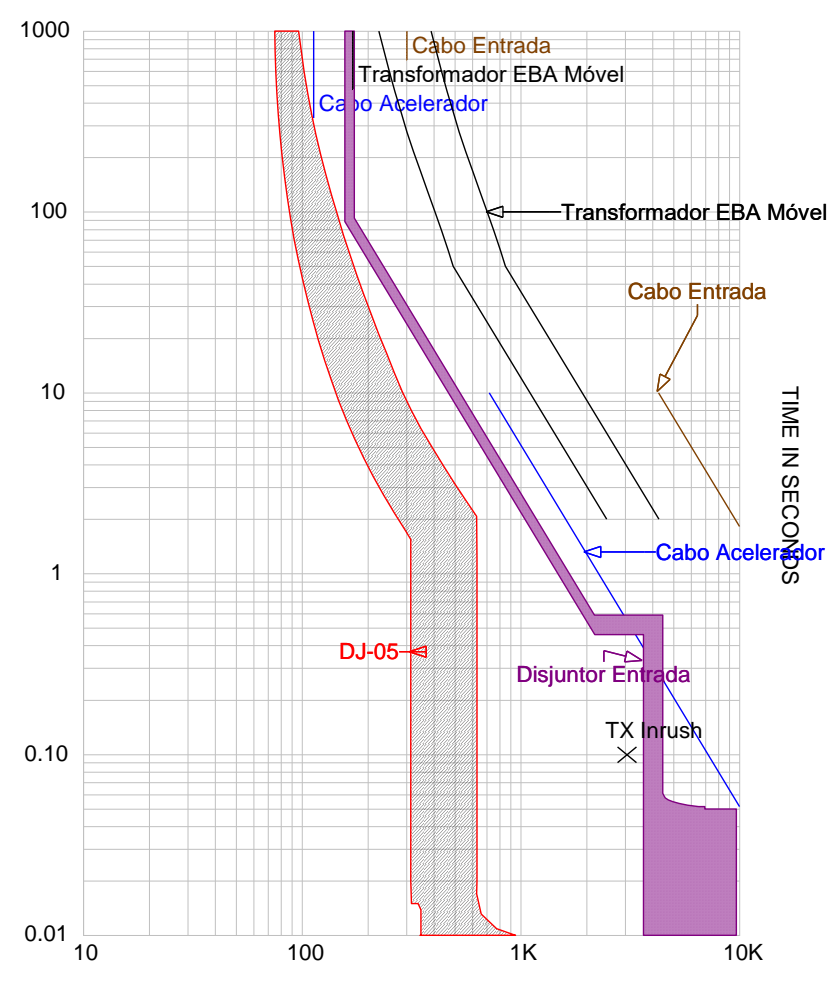

DJ Acelerador2.tcc Ref. Voltage: 380V Current in Amps x 1 InitSym 3P

Figura 11 - Coordenograma do trecho acelerador de elétrons até a conexão com a rede externa.
CURRENT IN AMPERES

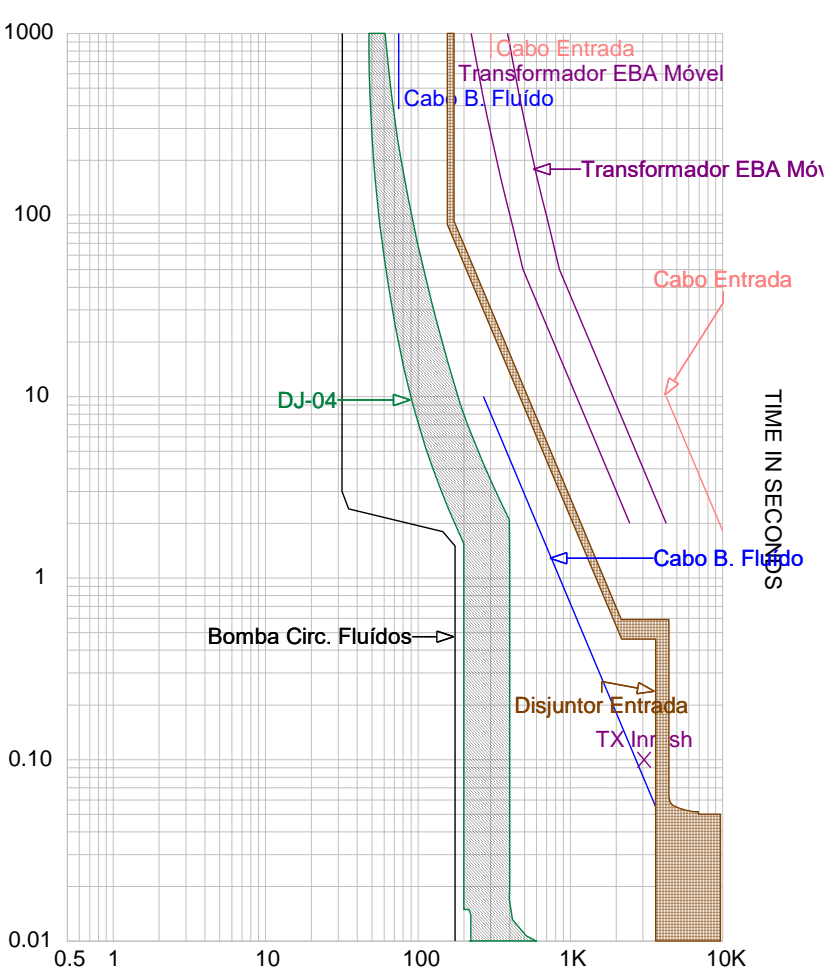

DJ Bomba2.tcc Ref. Voltage: 380V Current in Amps x 1 InitSym 3P DJ

Figura 12 - Coordenograma do trecho bomba de circulação de efluentes líquidos até a conexão com a rede externa.

O disjuntor de entrada, conforme já proposto, será de corrente nominal $300 \mathrm{~A}$ e curva ajustável tipo LSI (long/short/instantaneous). Dessa maneira, cada tensão de conexão deverá possuir um ajuste específico que garanta a proteção para sobrecargas. Na Tabela 5 são apresentados os valores que devem ser utilizados para cada nível de tensão elétrica.

Tabela 5 - Ajustes sugeridos na parametrização do disjuntor de entrada.

\begin{tabular}{|l|c|c|c|}
\hline \multicolumn{1}{|c|}{ Parâmetro } & Ajuste para 440 V & Ajuste para $\mathbf{3 8 0} \mathbf{~ V}$ & Ajuste para 220 V \\
\hline Proteção longa pick-up & $0,50 \mathrm{pu}(150 \mathrm{~A})$ & $0,60 \mathrm{pu}(180 \mathrm{~A})$ & $0,90 \mathrm{pu}(270 \mathrm{~A})$ \\
\hline Proteção longa delay & $2,5 \mathrm{~s}$ & $2,5 \mathrm{~s}$ & $2,5 \mathrm{~s}$ \\
\hline Proteção curta pick-up & $7 \mathrm{pu}(2.100 \mathrm{~A})$ & $7 \mathrm{pu}(2.100 \mathrm{~A})$ & $7 \mathrm{pu}(2.100 \mathrm{~A})$ \\
\hline Proteção curta delay & $0,5 \mathrm{~s}$ & $0,5 \mathrm{~s}$ & $0,5 \mathrm{~s}$ \\
\hline Proteção instantânea pick-up & $12 \mathrm{pu}(3.600 \mathrm{~A})$ & $12 \mathrm{pu}(3.600 \mathrm{~A})$ & OFF \\
\hline
\end{tabular}


O valor da corrente de magnetização considerado inicialmente foi o valor típico de 12 pu em 0,1 segundos conforme recomendação do IEEE [ $\left.{ }^{21}\right]$. Posteriormente este valor foi adequado para o valor informado pelo fabricante de 18pu. Como se observa, as proteções curta e instantânea devem ser mantidas idênticas para as tensões de $380 \mathrm{~V}$ e $440 \mathrm{~V}$. Na configuração em $220 \mathrm{~V}$, devido a magnitude da corrente de Inrush, não é possível fazer a coordenação corretamente, portanto o ajuste instantâneo deverá ser desabilitado nesta condição. Em todas as condições o ajuste garante a proteção da curva de danos do transformador (comumente chamado de ponto ANSI, representado pelas curvas em azul em paralelo), ou seja, antes de a corrente chegar a valores que danifiquem o transformador, deverá haver a atuação da proteção do disjuntor. A curva de danos do transformador utilizada foi calculada pelo próprio software através da impedância característica do transformador estimada em $4 \%$. Os disjuntores DJ-01 a DJ-10 foram dimensionados de forma a proteger os respectivos cabos e cargas durante um curto-circuito e para não atuarem durante a partida dos motores.

Os disjuntores relacionados ao acelerador de elétrons (DJ-05), bomba de vácuo iônica (DJ-03) e bomba de circulação de efluentes líquidos (DJ-02) deverão possuir bobinas de abertura de atuação instantânea, de modo a interromperem o processo imediatamente após a detecção de alguma anomalia. Isso se faz necessário para atender a CNEN NN $\left.3.01{ }^{22}\right]$, que dita às diretrizes básicas de proteção radiológica estabelecidas pela Comissão Nacional de Energia Nuclear (CNEN). A interrupção deverá ocorrer sempre que houver qualquer risco iminente às pessoas e trabalhadores envolvidos, tais como, violação das áreas onde há possibilidade de exposição à radiação ionizante, falha de algum sensor vital ao processo ou falha de controle.

\section{DESENVOLVIMENTO E AQUISIÇÃO DOS EQUIPAMENTOS}

Após finalizada a análise e estudos de todos equipamentos e particularidades da unidade móvel, foram elaboradas especificações e desenhos técnicos para compor a documentação necessária para iniciar o processo de aquisição, realizado por meio de pregões eletrônicos públicos. Após nivelamento técnico das empresas concorrentes, as vencedoras do certame procederam com a produção e entrega dos equipamentos para montagem da unidade móvel no IPEN. 
O transformador isolador foi fabricado com peculiaridades inerentes ao projeto, possuindo diversos níveis de tensão na entrada e saída. A Figuras 13 ilustra o resultado final da fabricação do transformador. A Figura 14 detalha parte superior do transformador configurado para a tensão de $220 \mathrm{~V}$ na entrada. A cada alteração do nível de tensão da planta industrial, é necessário configurar as ligações do enrolamento primário do transformador conforme a placa diagramática de modo a obter a tensão desejada para os equipamentos da unidade móvel. Outro ponto importante é a verificação da tensão correta na saída do transformador antes de ligar qualquer carga da unidade móvel, pois uma conexão errada pode gerar níveis de tensão maiores que os nominais e provocar a queima de equipamentos por exemplo.

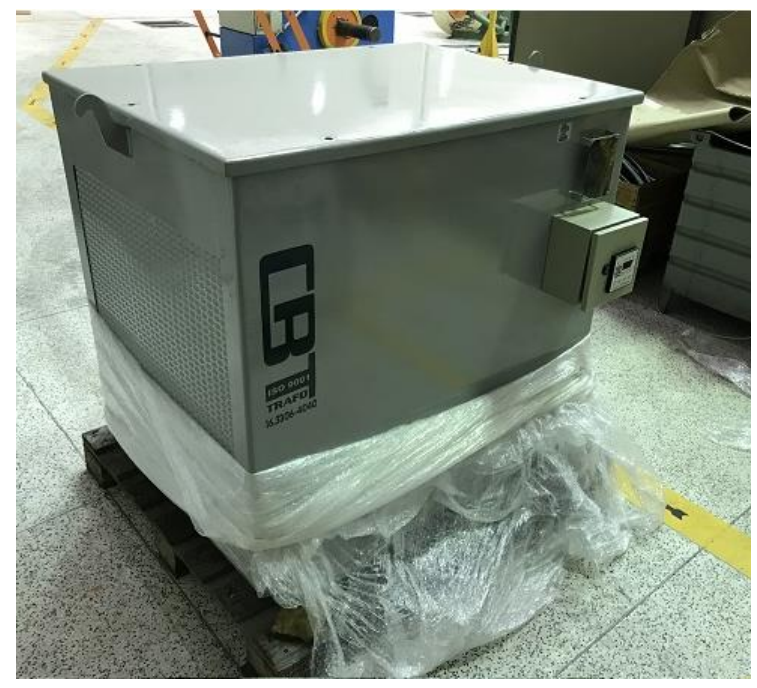

Figura 13 - Transformador Isolador adquirido de 112,5 kVA para a unidade móvel.

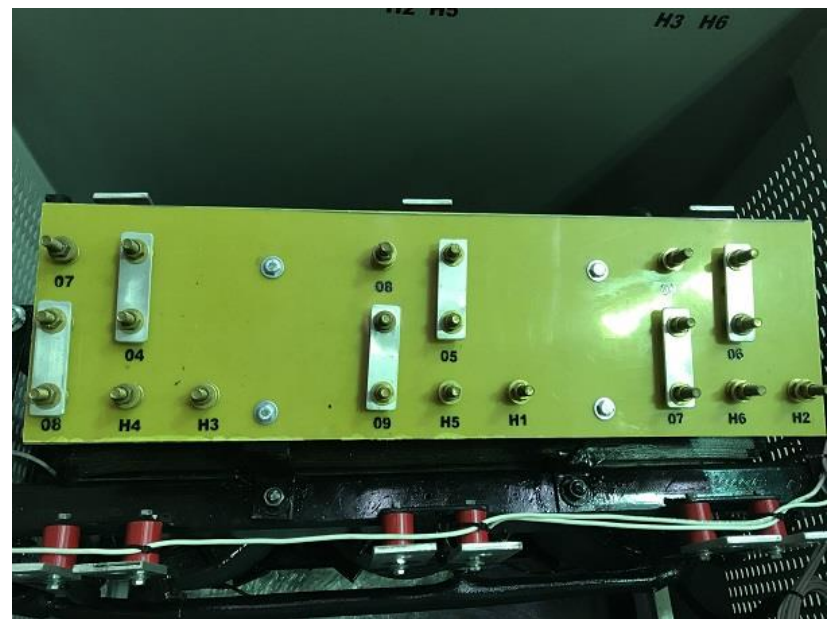

Figura 14 - Pontos de ligação do enrolamento primário e barras de conexão.

O quadro de distribuição foi montado conforme o projeto técnico aprovado, atendendo às cargas previstas incialmente. Os cabos estão previstos para entrarem na parte inferior e conectados na parte traseira do painel. Os disjuntores serão identificados, além do TAG operacional, pelos equipamentos que estarão alimentando. Para evitar conexões indevidas e propiciar o correto ajuste do disjuntor de entrada, será elaborada uma instrução de conexão que irá dentro do painel. $\mathrm{Na}$ instrução serão elencados em passo a passo os procedimentos para conexão e verificações necessárias antes da energização da unidade móvel como um todo. 


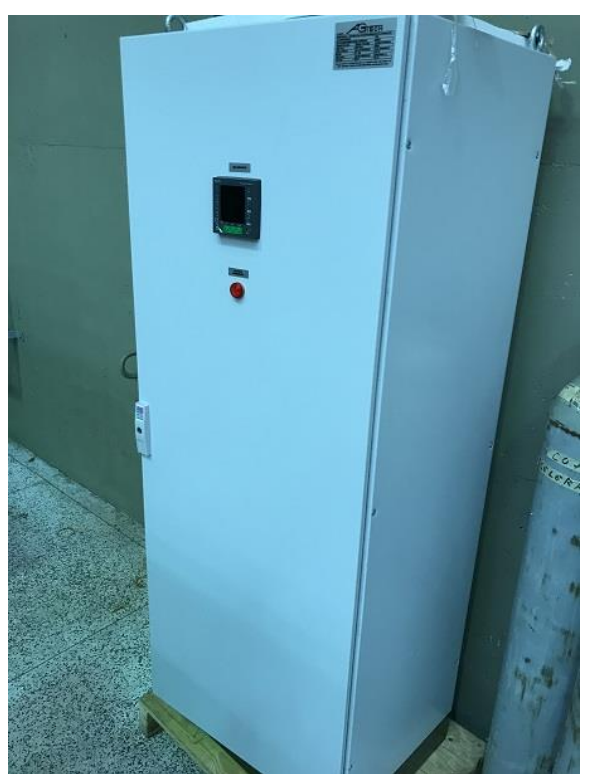

Figura 15 - Quadro de distribuição adquirido para a unidade móvel.

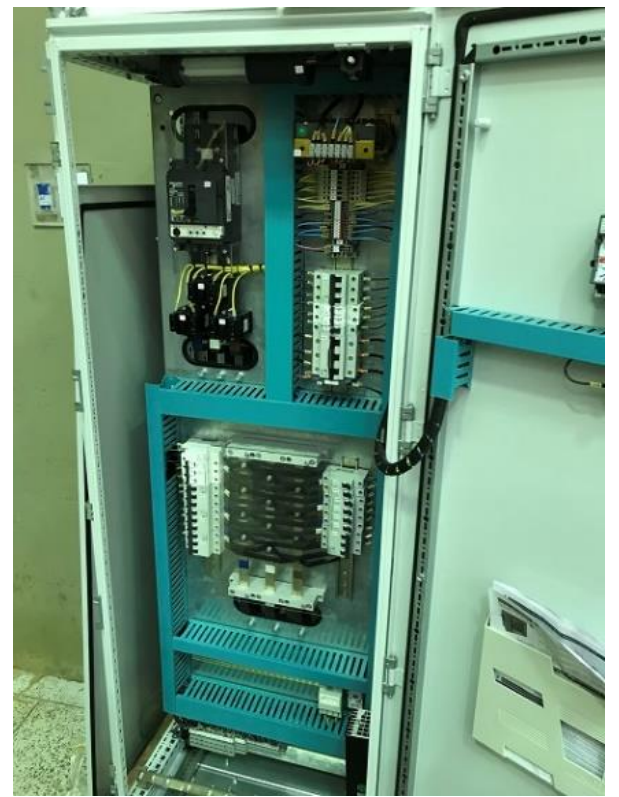

Figura 16 - Detalhe do quadro de distribuição.

Os demais equipamentos da unidade móvel, gerador diesel, cabos, bombas e o próprio acelerador de elétrons ainda estão em fase de aquisição, tendo sua previsão de entrega prevista para início de 2019.

\section{HARMÔNICOS}

Sabe-se que devido à natureza construtiva do acelerador de elétrons, baseada em circuitos osciladores e multiplicadores de tensão multi-estágios, a geração de correntes harmônicas na rede elétrica ocorre de forma constante e precisa ser monitorada para garantir a qualidade de energia, de forma a não afetar as demais cargas conectadas a essa rede, incluindo as cargas da indústria em que a unidade móvel será conectada.

A distorção harmônica é representada pela deformação da forma senoidal pura, ou seja, a forma de onda na frequência fundamental, que no caso do sistema elétrico Brasileiro é de $60 \mathrm{~Hz}$. Essa deformação pode ser ocasionada por diversos motivos, 
dentre eles a saturação dos núcleos magnéticos, reatores controlados por tiristores, fornos a arco e cargas eletrônicas, dentre outros.

A forma de onda distorcida pode ser decomposta pela série de Fourier para saber o conteúdo espectral. Para quantificar as distorções presentes do sistema, usualmente é utilizado o conceito de Distorção Harmônica Total (DHT), que é expresso na Equação 11:

$$
D H T=\sqrt{\sum_{h=2}^{50}\left(\frac{V_{h}}{V_{I}}\right)^{2}}
$$

Na qual, $V_{h}$ é o valor eficaz da tensão harmônica correspondente e $V_{l}$ o valor eficaz da tensão fundamental.

É possível observar que a taxa total de distorção consiste basicamente na somatória de todas as harmônicas, exceto a fundamental. Na prática, os livros e softwares limitam a soma até a 50ª harmônica desprezando as demais devido as baixas magnitudes. Alguns guias internacionais, tal como, o IEEE Std. 519 [23] e IEC IEC 61000-3-4 [ [24] sugerem limites para as taxas de distorção harmônica.

Pela IEEE os limites de distorções de tensão são classificados pelo nível de tensão do sistema, enquanto o limite de distorção de corrente pela potência de curto circuito. Na Tabela 6 são apresentados os limites aceitáveis de distorção harmônicos da tensão elétrica.

Tabela 6 - Limites harmônicos de tensão individual e da distorção total, publicados no guia IEEE Std. 519-2014 [23].

\begin{tabular}{|c|c|c|}
\hline $\begin{array}{c}\text { Tensão elétrica no ponto } \\
\text { de conexão (kV) }\end{array}$ & Harmônico individual (\%) & Distorção harmônica total (\%) \\
\hline$V<1$ & 5,0 & 8,0 \\
\hline $1<V<69$ & 3,0 & 5,0 \\
\hline $69<V<161$ & 1,5 & 2,5 \\
\hline $161<V$ & 1,0 & 1,5 \\
\hline
\end{tabular}

Para os harmônicos de corrente, os limites estão apresentados na Tabela 7, extraída do mesmo guia. A primeira coluna refere-se à relação da corrente de curtocircuito ISC pela corrente nominal $I_{L}$. As demais colunas referem-se às faixas harmônicas e seus limites. Na última coluna tem-se a distorção total de demanda TDD. 
Os harmônicos pares presentes dentro das faixas são limitados a $25 \%$ do valor expresso na mesma tabela.

Tabela 7 - Limites harmônicos de corrente individual e da distorção total, publicados no guia IEEE Std. 519-2014 [23].

\begin{tabular}{|c|c|c|c|c|c|c|}
\hline \multicolumn{7}{|c|}{ Distorção harmônica máxima da corrente em percentagem de $I_{L}$} \\
\hline$I_{S C} / I_{L}$ & $3 \leq h \leq 11$ & $11 \leq h \leq 17$ & $17 \leq h \leq 23$ & $23 \leq h \leq 35$ & $35 \leq h \leq 50$ & TDD \\
\hline$<20$ & 4,0 & 2,0 & 1,5 & 0,6 & 0,3 & 5,0 \\
\hline $20<50$ & 7,0 & 3,5 & 2,5 & 1,0 & 0,5 & 8,0 \\
\hline $50<100$ & 10,0 & 4,5 & 4,0 & 1,5 & 0,7 & 12,0 \\
\hline $100<1000$ & 12,0 & 5,5 & 5,0 & 2,0 & 1,0 & 15,0 \\
\hline$>1000$ & 15,0 & 7,0 & 6,0 & 2,5 & 1,4 & 20,0 \\
\hline
\end{tabular}

Já a norma IEC IEC 61000-3-4 [24] trata dos limites máximos de distorção harmônica de corrente para equipamentos de baixa tensão com corrente nominal entre $16 \mathrm{~A}$ e $75 \mathrm{~A}$. Os limites são expressos individualmente por ordem harmônica conforme a Tabela 8.

Tabela 8 - Limites harmônicos de corrente segundo IEC 61000-3-4 [24].

\begin{tabular}{|c|c|c|c|}
\hline $\begin{array}{c}\text { Ordem } \\
\text { Harmônica }\end{array}$ & $\begin{array}{c}\text { Corrente Harmônica } \\
\text { Admissível (In/l1) }\end{array}$ & $\begin{array}{c}\text { Ordem } \\
\text { Harmônica }\end{array}$ & $\begin{array}{c}\text { Corrente Harmônica } \\
\text { Admissível (In//1) }\end{array}$ \\
\hline $\mathbf{3}$ & 21,6 & $\mathbf{1 9}$ & 1,1 \\
\hline $\mathbf{5}$ & 10,7 & $\mathbf{2 1}$ & 1,1 \\
\hline $\mathbf{7}$ & 7,2 & $\mathbf{2 3}$ & $\leq 0,6$ \\
\hline $\mathbf{9}$ & 3,8 & $\mathbf{2 5}$ & 0,9 \\
\hline $\mathbf{1 1}$ & 3,1 & $\mathbf{2 7}$ & 0,8 \\
\hline $\mathbf{1 3}$ & 2 & $\mathbf{2 9}$ & $\leq 0,6$ \\
\hline $\mathbf{1 5}$ & 0,7 & $\mathbf{3 1}$ & 0,7 \\
\hline $\mathbf{1 7}$ & 1,2 & $\geq \mathbf{3 3}$ & 0,7 \\
\hline
\end{tabular}

Os efeitos ocasionados por altos índices de distorção harmônica já são conhecidos por diversos trabalhos publicados $\left[{ }^{25}\right]$, dentre eles destacam-se: 
- Surgimento de vibrações e ruídos;

- Aquecimento de núcleos ferromagnéticos;

- Aquecimento de capacitores;

- Erros de medições de grandezas elétricas;

- Aparecimento de tensões ou correntes ressonantes;

- Falha de controle de conversores;

- Atuação incorreta dos dispositivos de proteção e;

- Interferência e ruídos eletromagnéticos.

A redução do conteúdo harmônico depende basicamente da distribuição desses no espectro. Portanto primeiramente é necessário avaliar a contribuição real de cada ordem para permitir a dimensionamento de dispositivos de controle. A forma mais utilizada para mitigar os efeitos dos harmônicos é através da instalação de filtros sintonizados seja para uma ou diversas ordens, de modo a garantir um caminho de alta ou baixa impedâncias para os harmônicos dependendo do tipo de ligação.

\section{MEDIÇÕES REALIZADAS NO ACELERADOR DE ELÉTRONS}

Sabe-se que, em função da natureza construtiva do acelerador de elétrons, baseado em circuitos multiplicadores de tensão multi-estágios, a geração de correntes harmônicas na rede elétrica ocorre de forma constante e, portanto, necessita de avaliação para garantir a qualidade de energia e assim não afetar as demais cargas conectadas a essa rede, incluindo as cargas elétricas da indústria em que a Unidade Móvel será conectada.

Para facilitar o entendimento e permitir avaliar as características da carga que está sendo estudada, foi proposto analisar o sistema de potência de um Acelerador Industrial de Elétrons instalado no Centro de Tecnologia das Radiações, modelo RDI DC 1500/25/4, com energia de $1,5 \mathrm{MeV}$, corrente de feixe $25 \mathrm{~mA}$ e potência de feixe $37,5 \mathrm{~kW}$.

Para a medição dos parâmetros elétricos foi utilizado um medidor de qualidade de energia modelo Power Quality Meter (PQM) da marca $G E^{\odot}$. Este medidor possui capacidade de armazenamento das grandezas elétricas principais, registrador de 
eventos, disparo de oscilografias e análise harmônica total e de espectro harmônico até a $62^{\text {a }}$ ordem.

A transdução de corrente foi realizada por transformadores de corrente com relação 400 - $5 \mathrm{~A}$, classe $0,3 \mathrm{C}$ e 12,5 VA. As tensões foram medidas diretamente das barras de alimentação elétrica de $440 \mathrm{~V}$ trifásica, portanto não houve transdução de tensão. Nas Figuras 17 e 18 são mostrados os equipamentos utilizados no trabalho, no Centro de Tecnologia das Radiações do IPEN.

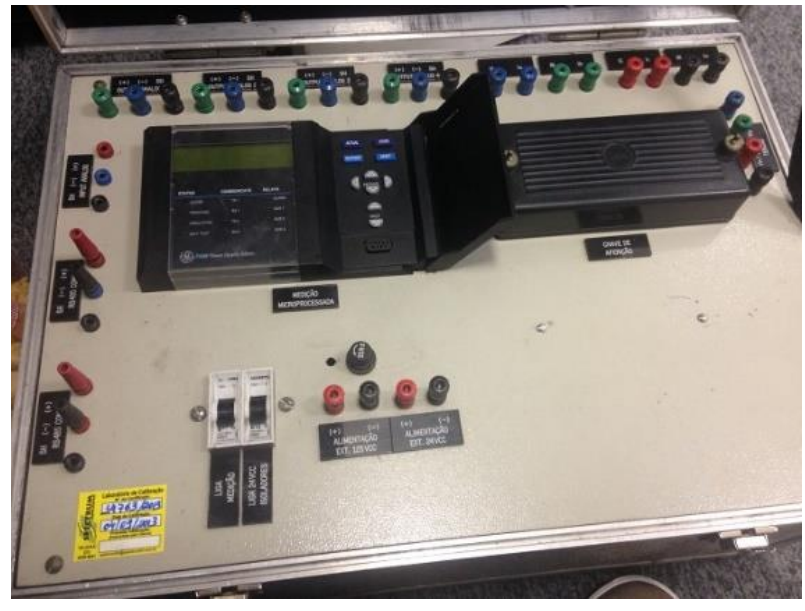

Figura 17 - Medidor de energia Power Quality Meter (PQM) da marca GEC.

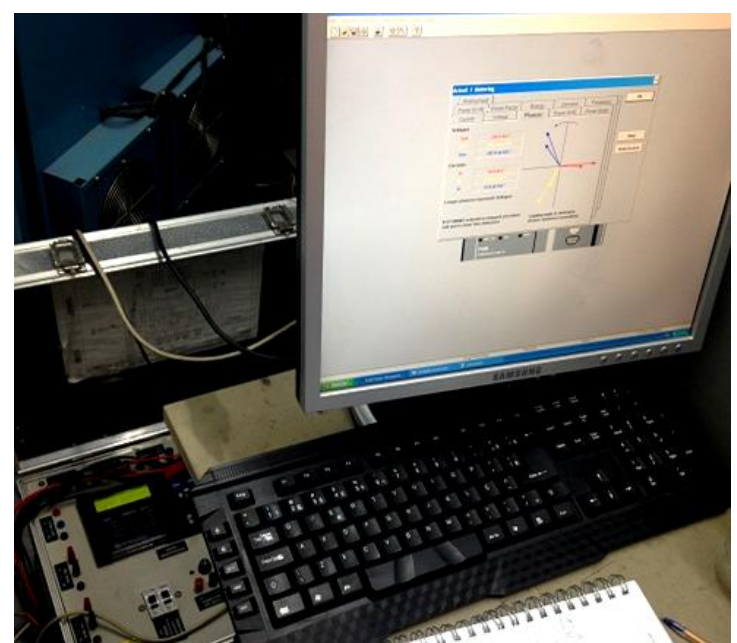

Figura 18 - Tela do software e medições no Centro de Tecnologia das Radiação.

Após acionado, o acelerador de elétrons foi submetido às variações de energia dos elétrons e corrente de feixe. Em cada degrau, registraram-se os principais parâmetros elétricos, incluindo os índices de distorção harmônicas. Nas Figuras 19 e 20 são mostrados os gráficos do comportamento da variação das distorções harmônicas de corrente e tensão pelo aumento da corrente de feixe de elétrons. Nas Figuras 21 e 22 são ilustradas as respectivas formas de onda de corrente e tensão. 


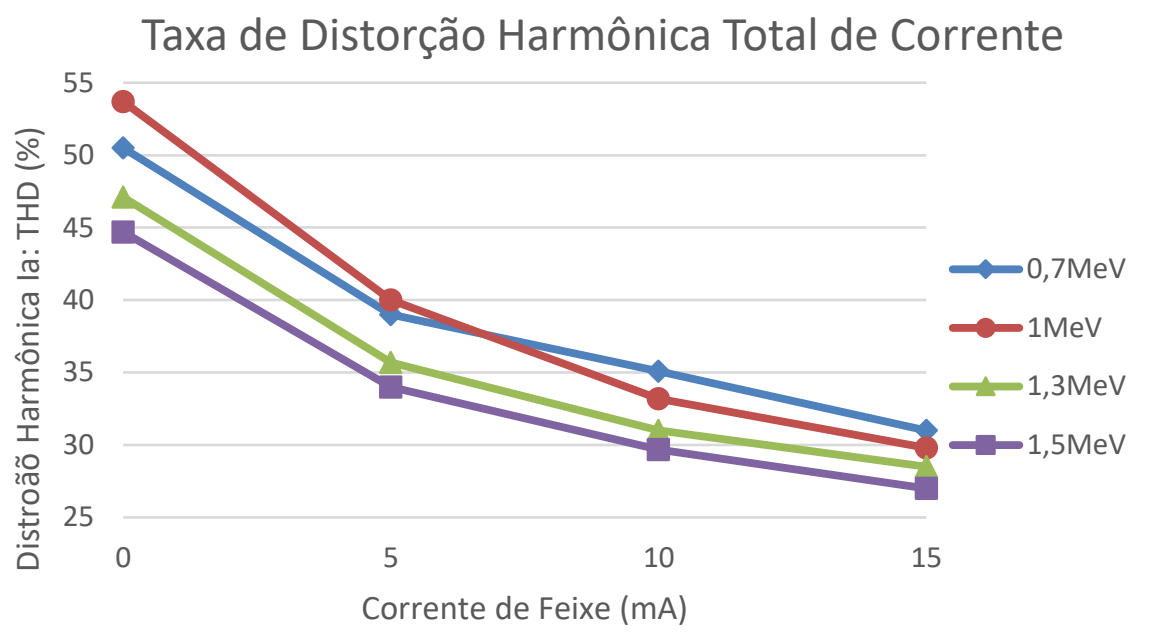

Figura 19 - Variação da distorção harmônica da corrente pela corrente do feixe de elétrons.

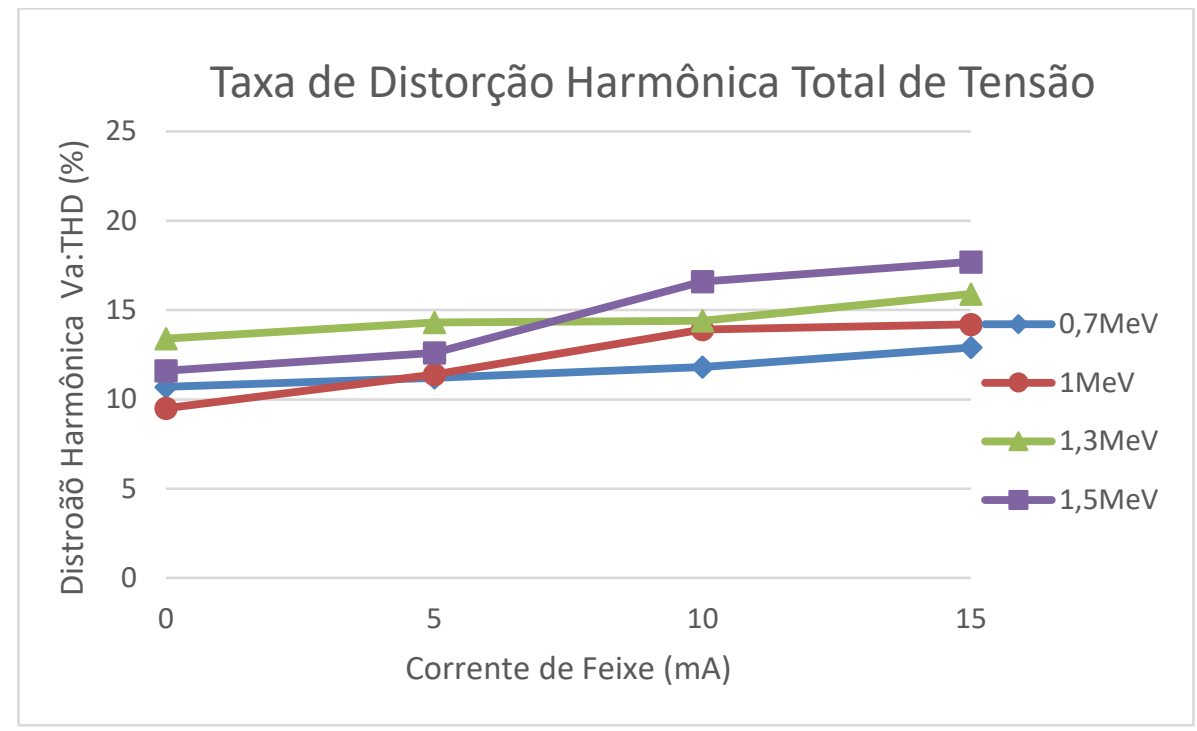

Figura 20 - Variação da distorção harmônica da tensão pela corrente do feixe de elétrons.

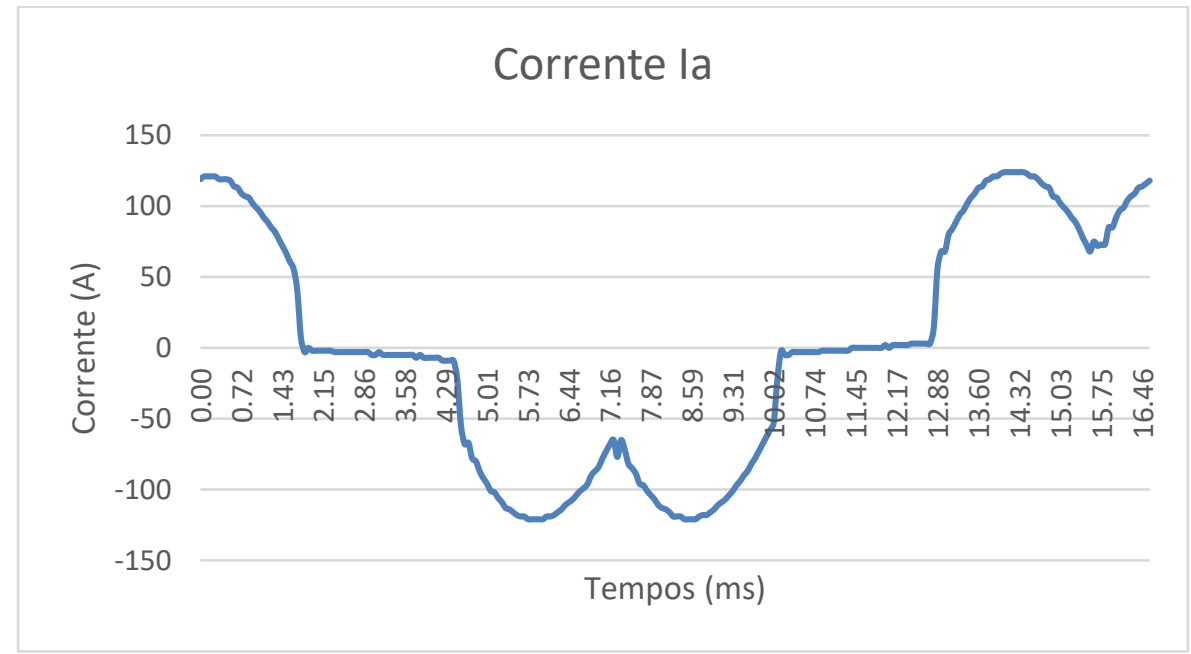

Figura 21 - Forma de onda típica da corrente na entrada do acelerador de elétrons. 


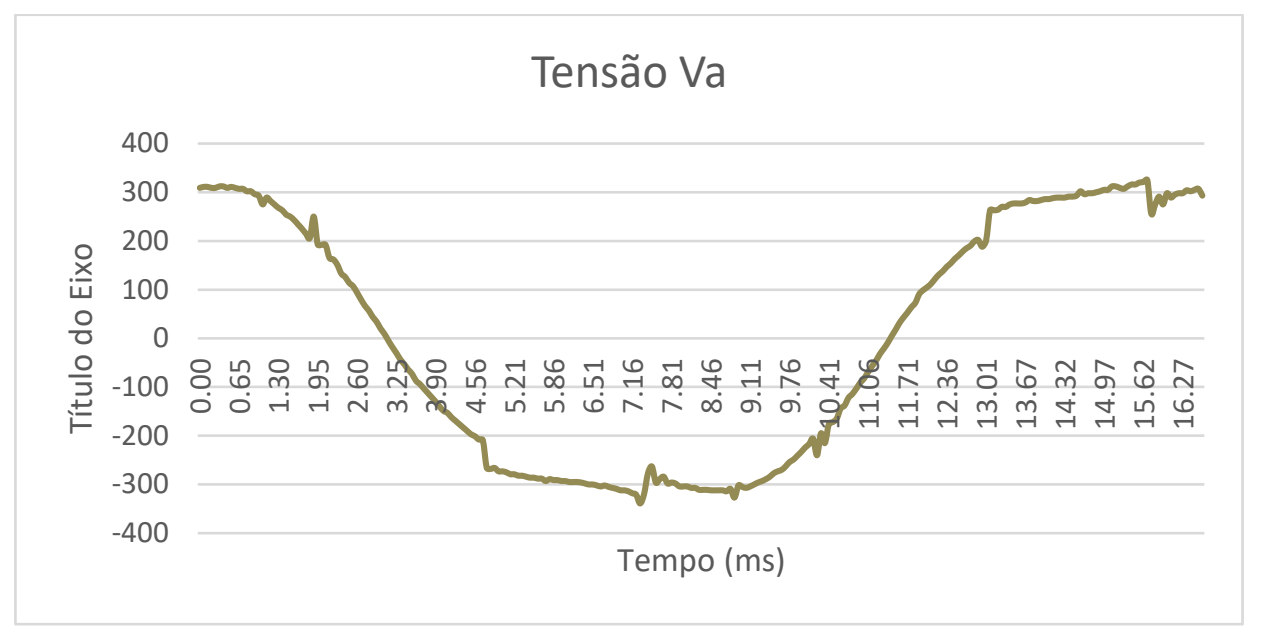

Figura 22 - Forma de onda típica da tensão na entrada do acelerador de elétrons.

A distorção harmônica é mais acentuada nos pontos com baixa corrente de feixe pois nesta condição tem-se somente o circuito de excitação do oscilador que é a principal fonte de não linearidade da carga. Com o aumento da potência do acelerador tem-se uma diminuição da distorção da corrente, porém um aumento da distorção de tensão conforme já esperado. Verifica-se também a característica bastante distorcida das formas de onda da corrente e tensão condizente com os índices apresentados. Ao se analisar quantitativamente os índices de distorção obtidos com os limites operacionais dos dispositivos normativos [23,24], percebe-se que em todas as faixas de operação do acelerador os limites de distorções harmônicas são superados. Nas Tabelas 9 e 10 são apresentados em vermelho, em valores percentuais, a superação dos índices de distorção harmônica da corrente e tensão, respectivamente, com o acelerador trabalhando na potência nominal (1,5MeV e $15 \mathrm{~mA}$ de feixe).

Tabela 9 - Comparação entre valores medidos no acelerador industrial de elétrons e os valores normatizados de distorção harmônica de corrente.

\begin{tabular}{|c|c|c|c|}
\hline $\begin{array}{c}\text { Ordem } \\
\text { Harmônica }\end{array}$ & $\begin{array}{c}\text { Limite IEC } \\
\mathbf{6 1 0 0 0 - 3 - 4} \text { (\%) }\end{array}$ & $\begin{array}{c}\text { Limite } \\
\text { IEEE-519 (\%) }\end{array}$ & $\begin{array}{c}\text { Valor Medido } \\
\mathbf{( \% )}\end{array}$ \\
\hline $\mathbf{3}$ & 21,6 & 12 & 2,09 \\
\hline $\mathbf{5}$ & 10,7 & 12 & 31,53 \\
\hline $\mathbf{7}$ & 7,2 & 12 & 4,26 \\
\hline $\mathbf{9}$ & 3,8 & 12 & 0,36 \\
\hline $\mathbf{1 1}$ & 3,1 & 5,5 & $\mathbf{7 , 2}$ \\
\hline
\end{tabular}




\begin{tabular}{|c|c|c|c|}
\hline $\mathbf{1 3}$ & 2 & 5,5 & 0,19 \\
\hline $\mathbf{1 5}$ & 0,7 & 5,5 & 0,22 \\
\hline $\mathbf{1 7}$ & 1,2 & 5 & 3,66 \\
\hline $\mathbf{1 9}$ & 1,1 & 5 & 0,51 \\
\hline $\mathbf{2 1}$ & $\leq 0,6$ & 5 & 0,11 \\
\hline $\mathbf{2 3}$ & 0,9 & 2 & $\mathbf{2 , 2 6}$ \\
\hline $\mathbf{2 5}$ & 0,8 & 2 & 0,62 \\
\hline $\mathbf{2 7}$ & $\leq 0,6$ & 2 & 0,1 \\
\hline $\mathbf{2 9}$ & 0,7 & 2 & 1,54 \\
\hline $\mathbf{3 1}$ & 0,7 & 2 & 0,68 \\
\hline $\mathbf{3 5}$ & $\leq 0,6$ & 2 & 1,13 \\
\hline
\end{tabular}

Tabela 10 - Comparação entre valores medidos no acelerador industrial de elétrons e os valores normatizados de distorção harmônica de tensão.

\begin{tabular}{|c|c|c|c|}
\hline $\begin{array}{c}\text { Ordem } \\
\text { Harmônica }\end{array}$ & $\begin{array}{c}\text { Limite } \\
\text { IEC6100-2-2 (\%) }\end{array}$ & $\begin{array}{c}\text { Limite } \\
\text { IEEE-519 (\%) }\end{array}$ & $\begin{array}{c}\text { Valor } \\
\text { Medido (\%) }\end{array}$ \\
\hline $\mathbf{3}$ & 5 & 5 & 18,5 \\
\hline $\mathbf{5}$ & 6 & 5 & 1,55 \\
\hline $\mathbf{7}$ & 5 & 5 & 0,51 \\
\hline $\mathbf{9}$ & 1,5 & 5 & 2,29 \\
\hline $\mathbf{1 1}$ & 3,5 & 5 & 0,59 \\
\hline $\mathbf{1 3}$ & 3 & 5 & 0,38 \\
\hline $\mathbf{1 7}$ & 2 & 5 & 0,56 \\
\hline Total & 8 & 5 & 19,2 \\
\hline
\end{tabular}

O acelerador industrial de elétrons em estudo localizado no Centro de Tecnologia das Radiações, então, foi submetido à energia de feixe de 0,7 MeV e corrente de $20 \mathrm{~mA}$, que são os parâmetros nominais do acelerador proposto para a Unidade Móvel de Irradiação.

Nessa condição, foram avaliadas as formas de onda das tensões e correntes resultantes da distorção harmônica envolvida. Os espectros harmônicos de corrente e tensão são mostrados nas Figuras 23 e 24, respectivamente. 


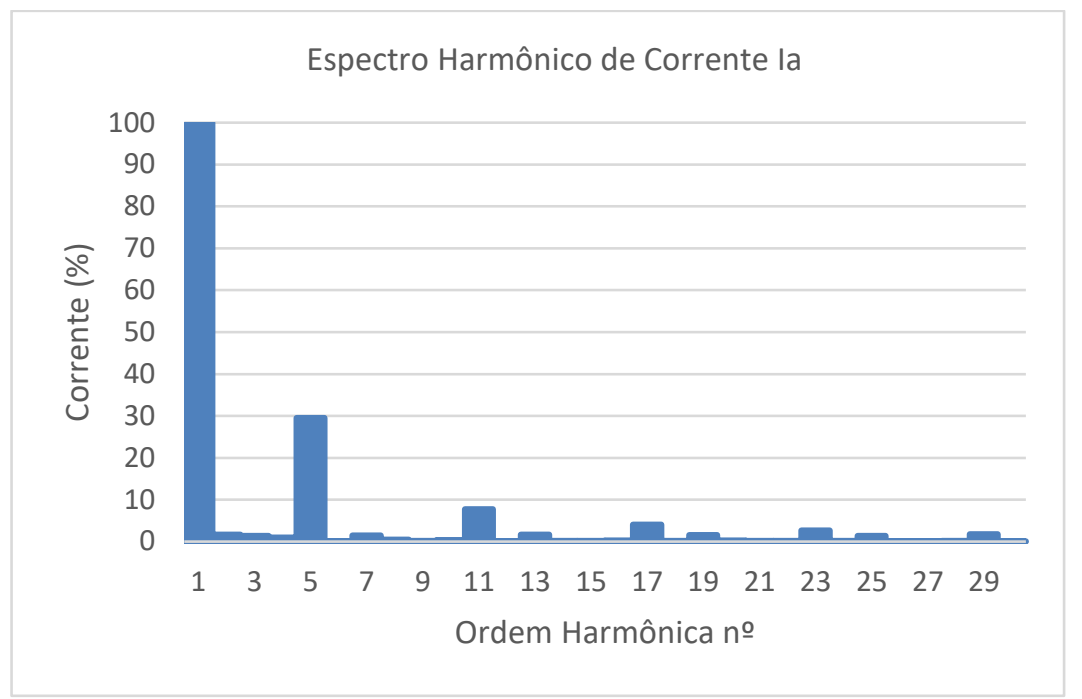

Figura 23 - Espectro harmônico da corrente la mantendo o acelerador na condição $0,7 \mathrm{MeV}$ e $20 \mathrm{~mA}$ de energia e corrente de feixe respectivamente.

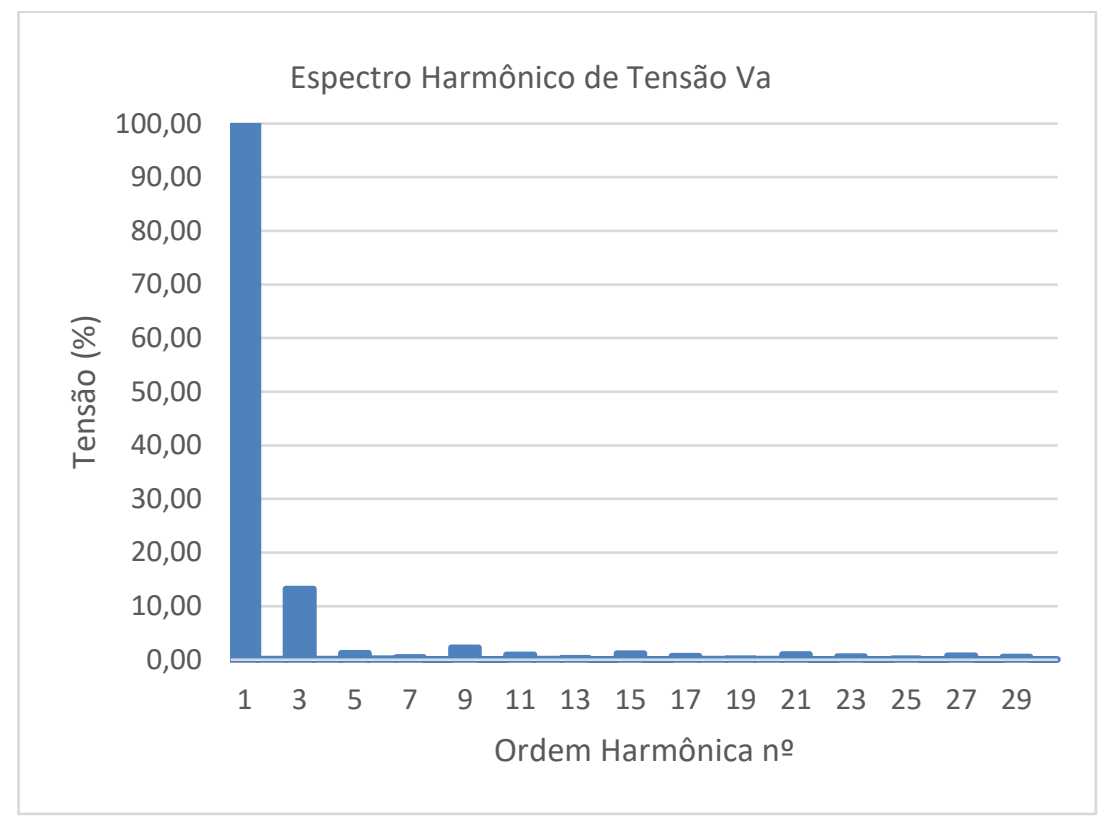

Figura 24 - Espectro harmônico da tensão Va mantendo o acelerador na condição $0,7 \mathrm{MeV}$ e $20 \mathrm{~mA}$ de energia e corrente de feixe respectivamente.

Analisando os espectros, é possível perceber as harmônicas mais presentes de corrente, $5^{\underline{a}}, 11^{a}$, $17^{a}$ e $23^{\underline{a}}$, enquanto para a tensão é de $3^{\underline{a}}$ ordem. Para se mitigar os índices encontrados, recomenda-se a instalação de filtros passivos sintonizados, próximos das frequências que se deseja eliminar. Para conteúdos harmônicos de altas frequências, um simples filtro passa-altas pode ser empregado para atenuar esses valores, não influenciando nas frequências próximas da fundamental. Uma vez empregado filtros para correção da distorção da corrente, é esperado também uma redução consequente da distorção de tensão. 
O cálculo e dimensionamento dos filtros devem seguir critérios normatizados, pois o incorreto dimensionamento pode acarretar a introdução de novas ressonâncias na rede e, consequentemente, o aparecimento de novas correntes de excitação, por isso deve ser analisado criteriosamente. Visando contribuir para a redução dos índices harmônicos encontrado, foi inserido no Anexo $A$ as fórmulas e procedimentos para o dimensionamento de um filtro harmônico passivo multisintonizado, juntamente com valores sugeridos inicialmente.

\section{CONCLUSÃO}

O desenvolvimento e aquisição dos componentes para a Unidade Móvel de Irradiação com acelerador industrial de elétrons é um marco importante para fomentar essa tecnologia ainda pouco utilizada no Brasil. Neste trabalho realizou-se o dimensionamento dos cabos elétricos, quadros de distribuição e disjuntores de acordo com as normas brasileiras vigentes, além da aquisição desses por meio de pregões eletrônicos no IPEN.

O dimensionamento dos cabos elétricos e do disjuntor de entrada representou um dos obstáculos encontrados, pois não é possível determinar as características elétricas do ponto de conexão, no qual Unidade Móvel será conectada. Nesse sentido, identificaram-se empresas que poderiam utilizar a Unidade Móvel e analisaram-se as características elétricas locais, que serviram como base para o dimensionamento dos equipamentos de entrada. De modo a garantir a utilização em uma variedade maior de indústrias, o disjuntor de entrada e o cabo de alimentação foram dimensionados para garantir maior proteção elétrica da Unidade Móvel. Nos casos onde não há nenhum dos níveis de tensão permitidos pela Unidade Móvel (440/380/220 Volts), será possível a utilização de gerador à diesel para demonstrações não contínuas, em função do elevado consumo de combustível.

A injeção de harmônicos ocasionada pela Unidade Móvel foi analisada por meio da medição direta da qualidade de energia de um acelerador de elétrons localizado no Centro de Tecnologia das Radiações do IPEN. Pela oscilografia das formas de onda da corrente e tensão, identificou-se o formato da natureza harmônica do acelerador industrial de elétrons (1,5 MeV e 37,5 kW). Em função dos altos valores apresentados do índice de distorção harmônica total, indica-se a necessidade da 
instalação de filtros para reduzir os efeitos indesejados causados pelos harmônicos. A necessidade de instalação de filtros na Unidade Móvel não pôde ser concluída, pois a natureza dos osciladores e ordem de grandeza das frequências são distintas.

A análise realizada até 0 momento nas plantas industriais que poderiam receber o acelerador de elétrons indica que não é simples a inserção de uma carga adicional de 112,5 kVA, mesmo em indústrias de grande porte, em razão dos cuidados que devem ser tomados quanto ao local da conexão elétrica, distância até a Unidade Móvel, tensão de operação, dentre outros. Demonstra-se que, para cada caso, é imprescindível a análise de um engenheiro eletricista de modo a autorizar ou não a conexão elétrica em sua planta industrial. Foram citados também diversos cuidados que se deve ter com a Unidade Móvel, tais como ajustar as conexões primárias do transformador isolador e as curvas de atuação do disjuntor de entrada de acordo com a tensão de operação. Quando utilizando o gerador a diesel, deve-se evitar partir todas as cargas e bombas simultaneamente e evitar a utilização do gerador a diesel operando por períodos longos.

\section{TRABALHOS FUTUROS}

Após a conclusão da montagem da Unidade Móvel de Irradiação e instalação em uma planta industrial, recomenda-se fazer novo levantamento das grandezas elétricas monitoradas, tais como de consumo, fator de potência e distorção harmônica individual e total. Para isso, previu-se a instalação de um medidor de energia no painel de distribuição elétrico específico para este fim. Com esses valores será permitido avaliar qual o índice real de distorção harmônica introduzido pela Unidade Móvel e, caso apresente valor acima dos normatizados, prever a inserção de filtros corretivos.

Para o acelerador industrial de elétrons (1,5 MeV e 37,5 kW) instalado no Centro de Tecnologia da Radiações do IPEN, é recomendado realizar uma análise mais completa do sistema elétrico local e propor a instalação de filtros multisintonizados para a redução dos índices medidos. 


\section{REFERÊNCIAS BIBLIOGRÁFICAS}

1. RELA, C. S. Estudo de Viabilidade Técnica e Econômica para implementação de uma unidade móvel para tratamento de efluentes industriais com feixe de elétrons. 2006. 76 p. Dissertação (Mestrado em Tecnologia Nuclear) - Instituto de Pesquisas Energéticas e Nucleares - IPEN-CNEN/SP. São Paulo.

2. LAS CASAS, A. Tratamento de Efluentes Industriais Utilizando a Radiação Ionizante de Acelerador Industrial de Elétrons e por Adsorção com Carvão Ativado. Estudo Comparativo. 2004. 86 p. Dissertação (Mestrado em Tecnologia Nuclear) - Instituto de Pesquisas Energéticas e Nucleares - IPEN-CNEN/SP. São Paulo.

3. DUARTE, C.L. Aplicação do Processo Avançado de Oxidação por feixes de Elétrons na Degradação de Compostos Orgânicos Presentes em Efluentes Industriais. 1999. 168 p. Tese (Doutorado em Tecnologia Nuclear) - Instituto de Pesquisas Energéticas e Nucleares - IPEN-CNEN/SP. São Paulo.

4. RELA, P.R. Desenvolvimento de Dispositivo de irradiação para tratamento de efluentes industriais com feixe de elétrons. 2003. Tese (Doutorado em Tecnologia Nuclear) - Instituto de Pesquisas Energéticas e Nucleares - IPENCNEN/SP. São Paulo.

5. STEERE, A.R. A Timeline of Major Particle Accelerator. 2005. Dissertação (Mestrado em Física) - Michigan State University, United States of America.

6. OLIVEIRA, H. B. "Acelerador de Partículas: História, Teoria e Aplicações". Artigo, Comissão Nacional de Energia Nuclear CNEN/SP, Instituto de Pesquisas Energéticas e Nucleares IPEN, Centro de Aceleradores Cíclotron CAC.

7. SOMESSARI L.S.; SOMESSARI E.S.R.; SILVEIRA C.G.; CALVO W.A.P; Analysis of the Power System from an Electron Beam Accelerator and the Correlation with the Theorical Dosimetry for Radiation Processing. International Nuclear Atlantic Conference - INAC 2013, 24-29 November, 2013.

8. MITTAL, K.C; MATHUR \& MANJULA S.A. "Electron Beam Accelerator for Water Pollution Control". Notas de aula, Bhabha Atomic Research Centre, Mumbai400085. 
9. High Voltage Environmental Application Inc. Disponível em: <http://cluin.org/products/site/ongoing/emertech/highvolt.htm>. Acessado em: 02 mar. 2015.

10. Fraunhofer Institut FEP and Schimdt-Seeger AG. E-ventus Pure Innovation. Obtido em: <http://www.e-ventus.de/index.php?setlang=en>. Acessado em: 20 jan. 2015.

11.GOLUBENKO, Y. I.; VEIS, M.E.; KUKSANOV, S.A.; KORABELNIKOV, B.M.; MALININ A.B.; NEMYTOV P.I.; PRUDNIKOV V.V.; PETROV S.E.; SALIMOV R.A.; CHEREPKOV V.G.; FADEEV S.N.; "Accelerators of ELV-type Status, development, aplications" Artigo Técnico, Radiation Physics and Chemistry 57(3-6) Março 2000.

12. PRESIDÊNCIA DA REPUBLICA, Casa Civil, Subchefia para Assuntos Jurídicos; Decreto № 41.019, DE 26 DE FEVEREIRO DE 1957.

13. ASSOCIAÇÃO BRASILEIRA DE NORMAS TÉCNICAS, NBR IEC 60694 Especificações comuns para normas de equipamentos de manobra de alta tensão e mecanismos de comando, versão 04 de dezembro de 2006.

14.ND-5.3 Norma de Distribuição, Fornecimento de Energia Elétrica em Média Tensão Rede de Distribuição Aérea ou Subterrânea, CEMIG, Set 2017.

15. HEIMER GRUPO GERADORES - Catálogo de Motores Diesel. Obtido em: <http://heimer.com.br/v4/br/assets/catalogo 2015 v.1.0.pdf> 20 jan. 2018.

16. PRESIDÊNCIA DA REPUBLICA, Casa Civil, Subchefia para Assuntos Jurídicos; DECRETO № 97.280, DE 16 DE DEZEMBRO DE 1988.

17. ASSOCIAÇÃO BRASILEIRA DE NORMAS TÉCNICAS, NBR $\mathbf{5 4 1 0}$ INSTALAÇÕES ELÉTRICAS DE BAIXA TENSÃO, versão 17 de março de 2008.

18. AGÊNCIA NACIONAL DE ENERGIA ELÉTRICA, NOTA TÉCNICA № 0153/2013SRD/ANEEL, 20 de Junho de 2013.

19. IEEE Std. C57.110-2008; IEEE Recommended Practice for Establishing LiquidFilled and Dry-Type Power and Distribution Transformer Capability When Supplying Nonsinuoidal Load Currents.

20.SHARIFIAN, M.B.B; FAIZ, J.; FAKHERI, S.A Derating of distribuition transformers for non-sinusoidal load currents using finite element method. IEEE Article 2003. p. $754-757$. 
21. IEEE Std. 242-2001; IEEE Recommended Practice for Protection and Coordination of Industrial and Commercial Power System.

22. COMISSÃO NACIONAL DE ENERGIA NUCLEAR, Diretrizes Básicas de Proteção Radiológica, 2005 (CNEN-3.0.1).

23. IEEE Std. 519-2014; IEE Recommended Practice and Requirements for Harmonic Control in Electric Power Systems".

24. IEC TS 61000-3-4:1998 Electromagnetic compatibility (EMC) - Part 3-4: Limits Limitation of emission of harmonic currents in low-voltage power supply systems for equipment with rated current greater than $16 \mathrm{~A}$.

25. WAGNER, V., et. al., Effects of Harmonics on Equipment, IEEE Trans. on Power Delivery. vol. 8, no. 2, pp 672-680, Apr. 1993.

26. IEEE Std. 1531-2003; Guide for Application and Specification of Harmonic Filters.

27. MORAIS, E. E. C. Estudo e Projeto de Filtros Passivos para atenuação de harmônicos em instalações elétricas industriais. 2011. 137 p. Trabalho Final de Curto (Graduação em Engenharia Elétrica). Universidade Federal do Ceará: Departamento de Engenharia Elétrica. Fortaleza.

28. TEIXEIRA, D. A.; Análise das Distorções Harmônicas - Estudo de Caso de um Sistema Industrial. 2009. 128p. Dissertação (Mestrado em Engenharia Elétrica) - Programa de Pós-Graduação em Tecnologia, Faculdade de Engenharia Elétrica, Universidade Federal de Minas Gerias - UFMG.

29.Calvo, W.A.P.; Duarte, C.L.; Machado, L.D.B.; Manzoli, J.E.; Geraldo, A.B.C.; Kodama, Y.; Silva, L.G.A.; Pino, E.S.; Poli, D.C.R.; Tobias, C.C.B.; Mathor, M.B.; Somessari, S.L.; Omi, N.M.; Somessari, E.S.R.; Silveira, C.G.; Rela, P.R.. Needs and Emerging Opportunities of Electron Beam Accelerators on Radiation Processing Technology for Industrial and Environmental Applications in South America. 2009. 18 p. International Topical Meeting on Nuclear Research Applications and Utilization of Accelerators, IAEA, Vienna, 4-8 May 2009.

30. Radiation Safety of Gamma, Electron and X Ray Irradiation Facilities. IAEA Safety Standards Series, Specific Safety Guide № SSG-8. International Atomic Energy Agency. 
31.Radiation Treatment of Polluted Water and Wastewater. International Atomic Energy Agency, September 2008 (IAEA-TECDOC-1598).

32. SAMPA, M.H.O.; RELA, P.R.; DUARTE, C.L. "Industrial Wastewater Treatment in Brazil Using Electron Beam Accelerator" Editors: William J. Cooper, Kevin E. O'Shea and Randolph D. Curry, in "Environmental Applications of lonizing Radiation” ,Capítulo 33, pages: 521-530, John Wiley \& Sounds, Inc., in 1998.

33. Rule Book - Alternative Transient Program ATP. CAUE - Comitê Argentino de Usuários de EMTP/ATP .

34. ANEEL 2016; "Procedimentos de Distribuição de Energia Elétrica no Sistema Elétrico Nacional - PRODIST Módulo 8 - Revisão 10 - Qualidade da Energia Elétrica".

35.NASCIMENTO, R.P.; RESENDE, J.W.; Procedimentos para determinação de filtros harmônicos sintonizados, incluindo análises de desempenho e de suportabilidade. Conferência Brasileira sobre Qualidade de Energia CBQEE, Santos (2008). 


\section{ANEXO A - DIMENSIONAMENTO DE FILTROS HARMÔNICOS}

Os índices harmônicos simulados para unidade móvel apresentaram valores totais inferiores aos limites estabelecidos pelas normas reguladoras existentes, porém não se pode dizer o mesmo para o acelerador industrial de elétrons (1,5 MeV e 37,5 kW) instalado no Centro de Tecnologia das Radiações. Os índices harmônicos ficaram $200 \%$ a 300\% acima dos limites de distorção harmônica total de corrente e tensão, o que sinaliza a necessidade da instalação de filtros harmônicos que propiciem a mitigação desses para níveis aceitáveis de distorção.

Os filtros basicamente possuem a função de criar um caminho de alta ou baixa impedância, restringido a carga a uma faixa específica de frequência. Essa característica pode ser obtida ao se utilizar uma combinação de elementos passivos, tais como resistores, capacitores e indutores, sejam conectados em série ou em derivação (shunt), ou utilizando-se elementos ativos, compostos por circuitos eletrônicos que analisam em tempo real os harmônicos presentes na rede e injetam valores antagônicos de forma a anular a distorção antes presente. A terceira opção é constituída por filtros híbridos, caracterizados pela mescla dos dois métodos descritos anteriormente.

Os filtros passivos do tipo shunt são os mais utilizados, em função da simplicidade e do baixo custo envolvido, porém necessitam de atenção dobrada no dimensionamento e escolha das ordens harmônicas que se deseja eliminar. Quando se pretende eliminar somente uma ordem harmônica, o filtro é denominado de sintonia simples, enquanto que o filtro que trabalha em mais de uma faixa é denominado de sintonia múltipla. A Figura A1 abaixo ilustra a forma de ligação do filtro shunt RLC de sintonia múltipla.

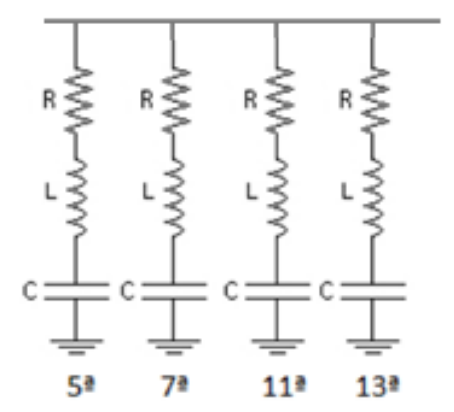

Figura A1- Filtro passivo $R L C$ shunt sintonizado $5^{\underline{a}}, 7^{a}, 11^{\underline{a}}$ e $13^{\underline{a}}$ ordens. 
Pela comparação realizada na Tabela 9 - Comparação entre valores medidos no acelerador industrial de elétrons e os valores normatizados de distorção harmônica de corrente, observa-se que as ordens harmônicas medidas no acelerador do Centro de Tecnologia das Radiações, que superaram os limites estipulados pela IEC e pela IEEE foram as harmônicas de $5^{\underline{a}}, 11^{\mathrm{a}}$ e $23^{\mathrm{a}}$ ordem.

No dimensionamento de filtros, uma prática recomendada pela IEEE $\left[{ }^{26}\right]$ é que o filtro seja sintonizado para uma frequência de $1,5 \%$ a $3 \%$ abaixo da frequência desejada. Esse percentual é denominado na literatura como fator de dessintonia $\delta$, utilizado basicamente para evitar o fenômeno de ressonância paralela devido a variações dos valores de impedância do equipamento, sistema ou inclusive devido a perdas das características físicas do filtro por envelhecimento. A Equação A1 ilustra o significado matemático do fator de dessintonia:

$$
\delta=\frac{\Delta f}{f_{n}}
$$

Onde $\delta$ é o fator de dessintonia, $f_{n}$ a frequência natural do harmônico e $\Delta f$ o deslocamento da frequência em hertz.

Considerando que o acelerador de elétrons não apresentou variações significativas da distribuição de harmônicos ao longo de sua faixa operativa, utilizouse um fator de dessintonia de $1,5 \%$, ou seja, um filtro de $5^{\circ}$ harmônico seria sintonizado na frequência de $295 \mathrm{~Hz}$. O ponto recomendado de instalação do filtro é o mais próximo possível da carga a ser corrigida, no caso, do acelerador de elétrons.

Inicialmente será projetado um filtro shunt de sintonia simples para a $5^{\text {a }}$ harmônica, que registrou a maior superação percentual. Em seguida será avaliado os filtros das demais ordens harmônicas superadas. A potência do filtro de cada harmônica pode ser calculada em função do percentual dos harmônicos medidos da $5^{\mathrm{a}}$ ordem conforme a Equação A2:

$$
Q_{5^{\mathrm{a}}}=P_{n o m} \cdot \frac{I_{5}}{\sum_{n=3,5,7 \ldots .} I_{n}}
$$

Somando todas as correntes percentuais da Tabela 9, e a potência total de consumo do acelerador industrial de elétrons sendo $80 \mathrm{kVA}$ tem-se a potência inicial estimada para o filtro, calculada por meio da Equação A2:

$$
Q_{5^{\mathrm{a}}}=80 \cdot \frac{31,53}{56,46}=45 \mathrm{kVA}
$$


Como a distorção harmônica registrada foi comum às três fases, o dimensionamento de uma fase será o mesmo para as demais. O cálculo dos parâmetros elétricos do filtro passivo ideal para um dado sistema é um processo iterativo que muitas vezes necessita de ferramentas computacionais. Para o cálculo inicial dos parâmetros pode-se utilizar as Equações A3 a A5 para cálculo das impedâncias indutivas, capacitivas e resistência.

$$
C=\frac{Q_{5^{\mathrm{a}}}}{2 \cdot \pi \cdot 60 \cdot\left(V_{L L}\right)^{2}}=616 \mu \mathrm{F}
$$

$\mathrm{Na}$ qual, VLL é a tensão nominal entre fases de entrada do circuito, de 440V.

Os demais valores necessários para dimensionamento do filtro são obtidos na sequência utilizando o fator de qualidade escolhido. $O$ fator de qualidade também é importante no projeto de filtros, definido pela razão da reatância indutiva e da resistência do filtro. Na prática, um filtro de alta qualidade indica menores perdas devido à baixa resistência, porém possui uma banda de dissintonia maior. Para a aplicação em baixa tensão usualmente são utilizados filtros com $Q=20$ a 50 [27,28]. Para o cálculo inicial será utilizado um fator de qualidade igual a 20. Desta maneira:

$$
\begin{gathered}
R=\frac{1}{2 \cdot \pi \cdot f_{s} \cdot C \cdot Q}=0,044 \Omega \\
L=\frac{R \cdot Q}{2 \cdot \pi \cdot f_{s}}=0,47 \mathrm{mH}
\end{gathered}
$$

Sendo $f_{s}$ a frequência de sintonia escolhida para mitigação, defasada pelo fator de dessintonia. O filtro projetado deve ser ligado em estrela aterrado com os valores similares para as três fases. Desta mesma forma, foi realizado o cálculo para as demais harmônica que superaram os limites estimados. O resultado obtido apresentando as demais características básicas sugeridas inicialmente, está apresentado na Tabela A1. 
Tabela A 1 - Características sugeridas para o filtro harmônico projetado.

\begin{tabular}{|c|c|c|c|}
\hline Grandeza & $\begin{array}{c}\text { Filtro } \\
\mathbf{5}^{\mathbf{2}} \text { Harmônica }\end{array}$ & $\begin{array}{c}\text { Filtro } \\
\mathbf{1 1}^{\text {a }} \text { Harmônica }\end{array}$ & $\begin{array}{c}\text { Filtro } \\
\mathbf{2 3}^{\text {Harmônica }}\end{array}$ \\
\hline Resistência nominal & $45 \mathrm{~m} \Omega$ & $9 \mathrm{~m} \Omega$ & $45 \mathrm{~m} \Omega$ \\
\hline Indutância nominal & $0,47 \mathrm{mH}$ & $0,43 \mathrm{mH}$ & $0,31 \mathrm{mH}$ \\
\hline Capacitância nominal & $616 \mu \mathrm{F}$ & $140 \mu \mathrm{F}$ & $44 \mu \mathrm{F}$ \\
\hline Corrente nominal & $60 \mathrm{~A}$ & $14 \mathrm{~A}$ & $4 \mathrm{~A}$ \\
\hline Fator de qualidade & 20 & 20 & 20 \\
\hline Tensão nominal & \multicolumn{3}{|c}{} \\
\hline $\begin{array}{c}\text { Nível básico de } \\
\text { isolamento }\end{array}$ & $600 \mathrm{~V}$ \\
\hline
\end{tabular}

Com os parâmetros determinados é possível conferir a frequência sintonizada pela fórmula:

$$
f_{\text {sintonizada }}=\frac{1}{2 \pi \sqrt{L C}}
$$

Deste modo as frequências sintonizadas foram $295 \mathrm{~Hz}, 648 \mathrm{~Hz}$ e $1362 \mathrm{~Hz}$ para os filtros projetados de $5^{\mathrm{a}}, 11^{\mathrm{a}}$ e $23^{\mathrm{a}}$ ordem harmônica, comprovando a dissintonia inserida. Por fim, foram inseridos os valores calculados no software ATPdraw de modo a avaliar o comportamento do filtro perante a variação da frequência. A figura A2 ilustra a resposta em frequência do filtro simulado:

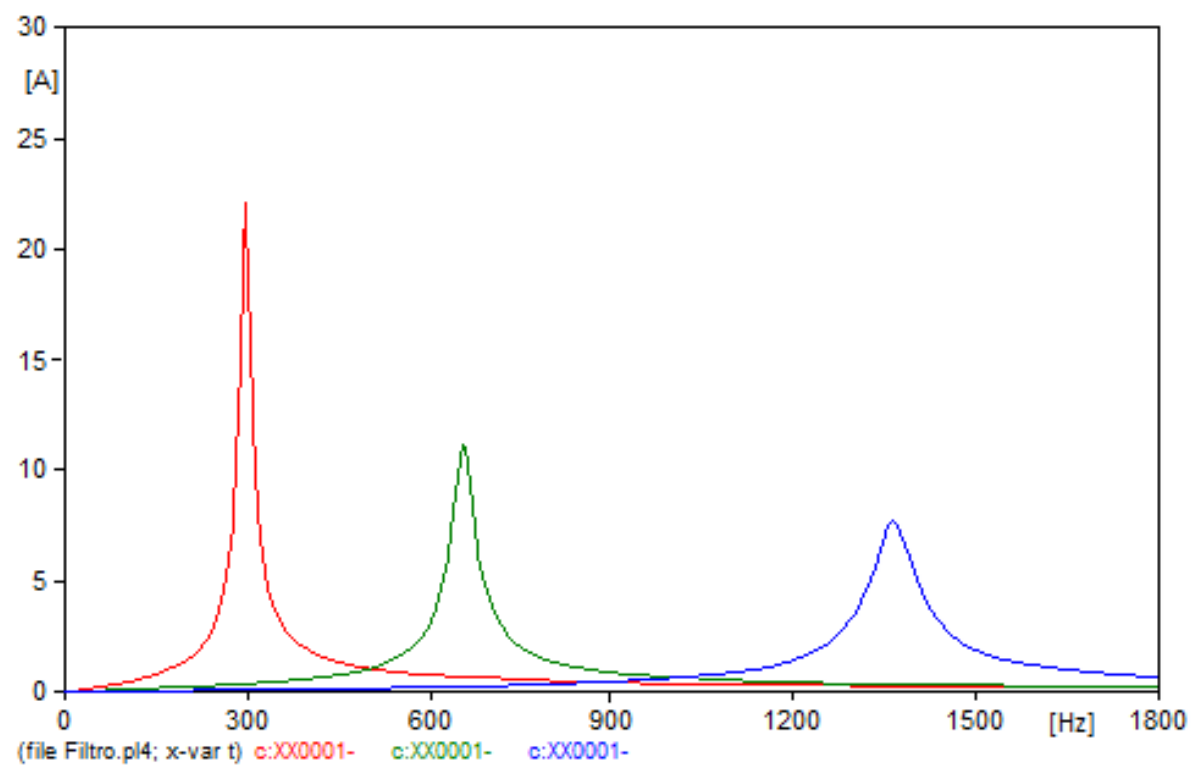

Figura A2- Resposta em frequência do filtro, simulado com o software ATPdraw. Em vermelho, verde e azul os filtros de $5^{\circ}, 11^{\circ}$ e $23^{\circ}$ ordem respectivamente. 
INSTITUTO DE PESQUISAS ENERGÉTICAS E NUCLEARES

Diretoria de Pesquisa, Desenvolvimento e Ensino

Av. Prof. Lineu Prestes, 2242 - Cidade Universitária CEP: 05508-000

Fone/Fax(0XX11) 3133-8908

SÃO PAULO - São Paulo - Brasil

http://www.ipen.br

O IPEN é uma Autaquia vinculada à Secretaria de Desenvolvimento, associada à Universiade de São Paulo e gerida técnica e administrativamente pela Comissão Nacional de Energia Nuclear, órgão do Ministério da Ciência, Tecnologia e Inovação. 